\title{
Preparation of Fluoroalkyl End-Capped Oligomer/Cyclodextrin Polymer Composites: Development of Fluorinated Composite Material Having a Higher Adsorption Ability toward Organic Molecules
}

\author{
Jun-Ichi Suzuki1,2, Yutaro Takegahara1, Yuri Oikawa1, Yuta Aomi1', Hideo Sawada1* \\ ${ }^{1}$ Department of Frontier Materials Chemistry, Graduate School of Science and Technology, Hirosaki University, \\ Hirosaki, Japan \\ ${ }^{2}$ Kankyo Kogaku, Hirosaki, Japan \\ Email: ^hideosaw@hirosaki-u.ac.jp
}

How to cite this paper: Suzuki, J.-I., Takegahara, Y., Oikawa, Y., Aomi, Y. and Sawada, H. (2018) Preparation of Fluoroalkyl End-Capped Oligomer/Cyclodextrin Polymer Composites: Development of Fluorinated Composite Material Having a Higher Adsorption Ability toward Organic Molecules. Journal of Encapsulation and Adsorption Sciences, 8, 117-138.

https://doi.org/10.4236/jeas.2018.82006

Received: May 2, 2018

Accepted: June 26, 2018

Published: June 29, 2018

Copyright (c) 2018 by authors and Scientific Research Publishing Inc. This work is licensed under the Creative Commons Attribution International License (CC BY 4.0).

http://creativecommons.org/licenses/by/4.0/

\section{(c) $\underset{\mathrm{EY}}{\mathrm{B}}$ Open Access}

\begin{abstract}
Fluoroalkyl end-capped vinyltrimethoxysilane oligomer $\left[\mathrm{R}_{\mathrm{F}}-\left(\mathrm{CH}_{2} \mathrm{CHSi}(\mathrm{OMe})_{3}\right)_{n}-\mathrm{R}_{\mathrm{F}} ; \mathrm{R}_{\mathrm{F}}=\mathrm{CF}\left(\mathrm{CF}_{3}\right) \mathrm{OCF}_{7}, n=2,3 ; \mathrm{R}_{\mathrm{F}}-(\mathrm{VM})_{n}-\mathrm{R}_{\mathrm{F}}\right]$ was applied to the preparation of fluoroalkyl end-capped vinyltrimethoxysilane oligomer $/ \alpha-, \beta-, \gamma$-cyclodextrin polymers $(\alpha-, \beta-, \gamma$-CDPs) composites $\left[\mathrm{R}_{\mathrm{F}}-\left(\mathrm{VM}-\mathrm{SiO}_{2}\right)_{n}-\mathrm{R}_{\mathrm{F}} / \alpha-, \beta-, \gamma-\mathrm{CDPs}\right]$ by the sol-gel reaction of the corresponding oligomer in the presence of the $\alpha$-, $\beta$-, $\gamma$-CDPs under alkaline conditions. The $\mathrm{R}_{\mathrm{F}}-\left(\mathrm{VM}-\mathrm{SiO}_{2}\right)_{n}-\mathrm{R}_{\mathrm{F}} / \alpha-, \beta-, \gamma$-CDPs composites thus obtained were found to give a good dispersibility toward the traditional organic media except for water, and were applied to the surface modification of glass to provide a sueperoleophilic/superhydrophobic characteristic on the modified surface, although the corresponding $\mathrm{R}_{\mathrm{F}}-\left(\mathrm{VM}-\mathrm{SiO}_{2}\right)_{n}-\mathrm{R}_{\mathrm{F}}$ nanocomposites can give a usual oleophobic/superhydrophobic property on the surface. These composites powders were also found to be applicable to the packing material for the column chromatography to separate the mixture of oil/water and the water in oil (W/O) emulsions. More interestingly, these composite powders were found to have a higher adsorption ability toward not only low-molecular weight aromatic compounds such as bisphenol A and bisphenol AF but also volatile organic compounds, compared to that of the pristine $\alpha-, \beta-, \gamma$-CDPs.
\end{abstract}

\section{Keywords}

Fluorinated Oligomeric Composite, Cyclodextrin Polymer, Surface 
Modification, Superoleophilic, Superhydrophobic Property, Separation of Oil and Water, Organic Molecule, VOC, Adsorption Ability

\section{Introduction}

There has been a great interest in cyclodextrins which consist of a hydrophilic exterior and a hydrophobic interior capable of binding small hydrophobic structures, due to their ability to form inclusion complexes with a wide variety of water-insoluble compounds [1] [2] [3] [4]. Cyclodextrins have been predominantly used for the stabilization, solubilization and formulation of drugs, and for the separation of the isomers and analogs in analytical chemistry [5] [6]. However, cyclodextrins possess a solubility toward water, limiting its reusability as the adsorbent for these compounds. Therefore, it is deeply desirable to develop the water-insoluble cyclodextrin polymers. In fact, there have been numerous reports on the synthesis of the water-insoluble cyclodextrin polymers by the use of epichlorohydrin and diisocyanates as the crosslinking agents, so far [7] [8] [9] [10] [11]. These water-insoluble cyclodextrin polymers thus obtained have been applied to the adsorbents for the organic pollutants such as phenol, p-nitrophenol, benzoic acid, $p$-nitrobenzoic acid, 4- $t$-butylbenzoic acid, and bisphenol A [12] [13] [14]. Hitherto, we have been comprehensively studying on the synthesis and applications of two fluoroalkyl end-capped oligomers $\left[\mathrm{R}_{\mathrm{F}}-(\mathrm{M})_{n}-\mathrm{R}_{\mathrm{F}} ; \mathrm{R}_{\mathrm{F}}=\right.$ fluoroalkyl group, $\mathrm{M}=$ radical polymerizable monomer] by the use of fluoroalkanoyl peroxide $\left[\mathrm{R}_{\mathrm{F}}-\mathrm{C}(=\mathrm{O})-\mathrm{OO}-(\mathrm{O}=) \mathrm{C}-\mathrm{R}_{\mathrm{F}}\right]$ as a key intermediate [15] [16] [17] [18] [19]. In these two fluoroalkyl end-capped oligomers, especially, two fluoroalkyl end-capped vinyltrimethoxysilane oligomers $\left[\mathrm{R}_{\mathrm{F}}-\left(\mathrm{CH}_{2} \mathrm{CHSi}\left(\mathrm{OMe}_{3}\right)_{n}-\mathrm{R}_{\mathrm{F}} ; \mathrm{R}_{\mathrm{F}}=\right.\right.$ $\mathrm{CF}\left(\mathrm{CF}_{3}\right) \mathrm{OC}_{3} \mathrm{~F}_{7}$ ] have been already applied to the composite reactions with not only talc fine particles in the presence of low-molecular weight organic molecules but also organic polymers such as poly (tetrafluoroethylene) fine particles to afford the corresponding fluorinated oligomeric silica nanocomposites encapsulated these guest molecules [20] [21] [22]. It was also demonstrated that these fluorinated nanocomposites can exhibit a superoleohilic/superhydrophobic characteristic toward the modified surface, although the corresponding original fluorinated oligomeric silica nanoparticles $\left[\mathrm{R}_{\mathrm{F}}-\left(\mathrm{CH}_{2} \mathrm{CHSiO}\right)_{n}-\mathrm{R}_{\mathrm{F}}\right]$ can give a usual oleophobic/superhydrophobic property on their modified surface [20]. In addition, these fluorinated nanocomposites are applicable to the packing materials for the column chromatography to separate the mixture of oil and water [21] [22]. From the developmental viewpoint of the cyclodextrin polymer derivatives possessing a higher adsorption ability toward a variety of organic molecules in aqueous media than that of the pristine cyclodextrin polymers, it is of particular interest to explore the cyclodextrin polymer derivatives possessing a superoleophilic/superhydropobic characteristic; however, such studies have been heretofore very limited. Here we report that two fluoroalkyl end-capped vinyltrimethoxysilane oligomers can be applicable to the sol-gel reaction in the presence of 
$\alpha$-, $\beta$-, $\gamma$-cyclodextrin polymers ( $\alpha-, \beta-, \gamma$-CDPs) under alkaline conditions to afford the corresponding fluorinated oligomeric silica/ $\alpha-, \beta-, \gamma$-CDPs composites. Interestingly, these fluorinated composites thus obtained were found to provide a higher adsorption ability toward low-molecular weight aromatic compounds such as bisphenol $\mathrm{A}$ and bisphenol $\mathrm{AF}$ in the aqueous solutions than that of the pristine $\alpha-, \beta-, \gamma$-CDPs. More interestingly, a higher adsorption behavior toward the volatile organic compounds such as toluene, xylenes, trichloroethylene and tetrachloroethylene was also observed by using these fluorinated composites. These results will be described in this article.

\section{Experimental}

\subsection{Measurements}

Dynamic light scattering (DLS) measurements were measured by using Otsuka Electronics DLS-7000 HL (Tokyo, Japan). Micrometer size-controlled composite particles were measured by using laser diffraction particle size analyzer: Shimadzu SALD-200 V (Kyoto, Japan). Field emission scanning electron micrographs (FE-SEM) were obtained using JEOL JSM-7000F (Tokyo, Japan). Thermal analyses were recorded on NETZSCH JAPAN TG-DTA2010SE $\alpha$ differential thermobalance (Kanagawa, Japan). Contact angles were measured using a Kyowa Interface Science Drop Master 300 (Saitama, Japan). Dynamic force microscopy (DFM) was recorded by using SII Nano Technology Inc. E-sweep (Chiba, Japan).HPLC (high performance liquid chromatography) analyses were conducted on a Shimadzu LC10A (Kyoto, Japan). GC-Mass spectra were recorded on a JEOL JMS-Q1000GC K9 (Tokyo, Japan).

\subsection{Materials}

$\alpha$-, $\beta$ - and $\gamma$-cyclodextrin polymers ( $\alpha$-, $\beta$-, $\gamma$-CDPs) were received from Kankyo Kogaku (Hirosaki, Japan). Fluoroalkyl end-capped vinyltrimethoxysilane oligomer $\left[\mathrm{R}_{\mathrm{F}}-\left(\mathrm{CH}_{2} \mathrm{CHSi}(\mathrm{OMe})_{3}\right)_{n}-\mathrm{R}_{\mathrm{F}}: n=2,3 ; \mathrm{R}_{\mathrm{F}}=\mathrm{CF}\left(\mathrm{CF}_{3}\right) \mathrm{OC}_{3} \mathrm{~F}_{7}: \mathrm{R}_{\mathrm{F}}-(\mathrm{VM})_{n}-\mathrm{R}_{\mathrm{F}}\right]$ was synthesized according to our previously reported method. [23] Glass plate (borosilicate glass) [micro cover glass: $18 \mathrm{~mm} \times 18 \mathrm{~mm}$ ] was purchased from Matsunami glass Ind. Ltd. (Osaka, Japan) and was used after washing well with 1,2-dichloromethane. Bisphenol $\mathrm{A}$ and bisphenol $\mathrm{AF}$ were purchased from Tokyo Chemical Industrial Co. (Tokyo, Japan).

1) Preparation of fluoroalkyl end-capped vinyltrimethoxysilane oligomeric silica/ $\alpha$-CDP composites $\left[\mathrm{R}_{\mathrm{F}}-\left(\mathrm{VM}-\mathrm{SiO}_{2}\right)_{n}-\mathrm{R}_{\mathrm{F}} / \alpha-\mathrm{CDP}\right]$

A typical procedure for the preparation of $\mathrm{R}_{\mathrm{F}}-\left(\mathrm{VM}-\mathrm{SiO}_{2}\right)_{n}-\mathrm{R}_{\mathrm{F}} / \alpha-\mathrm{CDP}$ composites is as follows: To methanol solution $(5 \mathrm{ml})$ containing fluoroalkyl end-capped vinyltrimethoxysilane oligomer $\left[\mathrm{R}_{\mathrm{F}}-(\mathrm{VM})_{n}-\mathrm{R}_{\mathrm{F}}\right](300 \mathrm{mg})$ was added $\alpha$-CDP $(10 \mathrm{mg})$. The mixture was stirred with a magnetic stirring bar at room temperature for $10 \mathrm{~min} .25 \%$ aqueous ammonia solution $(1.0 \mathrm{ml})$ was added to the methanol solution, and was successively stirred at room temperature for 5 hrs. After the solvent was evaporated off, methanol was added to the obtained 
crude products. The methanol suspension thus obtained was stirred with magnetic stirring bar at room temperature for 1 day, and then was centrifuged for 30 $\min$. The expected fluorinated oligomeric silica/ $\alpha$-CDP composites were easily separated from the methanol solution, and were successively washed several times with methanol. After centrifugal separation of this solution, the obtained product was dried under vacuum at $50^{\circ} \mathrm{C}$ for 1 day to produce the purified fluorinated composite white colored powders $(190 \mathrm{mg})$. Other fluorinated composites were prepared under similar conditions.

2) Surface modification of glass treated with the $\mathrm{R}_{\mathrm{F}}-\left(\mathrm{VM}-\mathrm{SiO}_{2}\right)_{n}-\mathrm{R}_{\mathrm{F}} / \alpha$-CDP composites

To methanol solution ( $5 \mathrm{ml}$ ) containing $\mathrm{R}_{\mathrm{F}}-(\mathrm{VM})_{n}-\mathrm{R}_{\mathrm{F}}$ oligomer (300 mg) was added $\alpha$-CDP $(10 \mathrm{mg})$. The mixture was stirred with a magnetic stirring bar at room temperature for $10 \mathrm{~min}$. $25 \%$ aqueous ammonia solution $(1.0 \mathrm{ml})$ was added to the methanol solution, and was successively stirred at room temperature for $5 \mathrm{hrs}$. The glass plate was dipped into this methanol solution at room temperature and left for $1 \mathrm{~min}$. These glass plates were lifted from the solutions at a constant rate of $0.5 \mathrm{~mm} / \mathrm{min}$ and subjected to the treatment for 1 day at room temperature; finally, these were dried under vacuum for 1 day at room temperature. After drying, the contact angles of dodecane and water were measured by the deposit of each droplet $(2 \mu \mathrm{l})$ on the modified glasses.

3) Preparation of the surfactant-stabilized water in oil (toluene) emulsion

The surfactant (span 80:30 mg) was added into the mixture of water $(0.05 \mathrm{ml})$ and toluene $(5.0 \mathrm{ml})$. The expected white-colored $\mathrm{W} / \mathrm{O}$ emulsion was easily prepared through the ultrasonic irradiation of the obtained mixture for $5 \mathrm{~min}$ at room temperature. Other W/O (oil: 1,2-dichloroethane) emulsion was also prepared under similar conditions.

4) Adsorption of bisphenol $\mathrm{A}$ in the aqueous solution by using the $\mathrm{R}_{\mathrm{F}}-\left(\mathrm{CH}_{2} \mathrm{CHSiO}_{2}\right)_{n}-\mathrm{R}_{\mathrm{F}} / \beta$-CDPs composites

Solid-phase extraction cartridge connected with the polyethylene frit containing the $\mathrm{R}_{\mathrm{F}}-\left(\mathrm{CH}_{2} \mathrm{CHSiO}_{2}\right)_{n}-\mathrm{R}_{\mathrm{F}} / \beta$-CDPs composite powders $(20 \mathrm{mg}$ : Run $20 \mathrm{in} \mathrm{Ta}-$ ble 1) was used for the adsorption of bisphenol A. $5 \mathrm{ml}$ of aqueous methanol solution (concentration of methanol: 6\%) containing bisphenol A $\left(0.1 \mathrm{mmol} / \mathrm{dm}^{3}\right)$ was applied to the cartridge, and the obtained eluent was analyzed by HPLC [Shimadzu LC10A; column: RP-18PA ${ }^{\mathrm{TR}}$ (4.6 mm I.D. = $150 \mathrm{~mm}$ ); injection volume: $10 \mathrm{ml}$; mobile phase: methanol/water/phosphoric acid (70.0/29.9/0.1 (vol/vol/vol); detection wavelength: $278 \mathrm{~nm}$ ] to detect the residual bisphenol A. Schematic process for analyzing the residual bisphenol A was illustrated in Scheme 2, and the residual bisphenol AF was also analyzed under similar conditions. In addition, Schematic illustration for the adsorption and desorption of $\mathrm{BPA}$ through the recycling process by using the $\mathrm{R}_{\mathrm{F}}-\left(\mathrm{CH}_{2} \mathrm{CHSiO}_{2}\right)_{n}-\mathrm{R}_{\mathrm{F}} / \beta$-CDPs composite powders as the packing material is shown in Scheme 3.

5) Adsorption of volatile organic compounds (VOCs) in the aqueous solutions by using the $\mathrm{R}_{\mathrm{F}}-\left(\mathrm{CH}_{2} \mathrm{CHSiO}_{2}\right)_{n}-\mathrm{R}_{\mathrm{F}} / \mathrm{CDPs}$ composites 
Table 1. Preparation of $\mathrm{R}_{\mathrm{F}}-\left(\mathrm{VM}-\mathrm{SiO}_{2}\right)_{n}-\mathrm{R}_{\mathrm{F}} / \alpha-, \beta-, \gamma-\mathrm{CDPs}$ composites.

\begin{tabular}{|c|c|c|c|c|c|c|}
\hline \multirow{2}{*}{ Run } & CDPs & $\mathrm{R}_{\mathrm{F}}-(\mathrm{VM})_{n}-\mathrm{R}_{\mathrm{F}}$ & $\mathrm{MeOH}$ & aq. $\mathrm{NH}_{3}$ & Yield $^{\text {a) }}$ & Size of the composites ${ }^{\mathrm{b})}$ \\
\hline & (mg) & $(\mathrm{ml})$ & $(\mathrm{ml})$ & $(\mathrm{ml})$ & (\%) & $(\mu \mathrm{m})$ \\
\hline 1 & $\alpha$-CDP (10) & 300 & 5 & 1 & 38 & $5.2 \pm 0.4$ \\
\hline 2 & $\beta$-CDP (10) & 300 & 5 & 1 & 56 & $2.8 \pm 0.2$ \\
\hline 3 & $\gamma$-CDP (10) & 300 & 5 & 1 & 40 & $4.9 \pm 0.3$ \\
\hline 4 & $\alpha-\operatorname{CDP}(25)$ & 300 & 5 & 1 & 61 & $6.7 \pm 0.4$ \\
\hline 5 & $\beta$-CDP (25) & 300 & 5 & 1 & 53 & $4.1 \pm 0.2$ \\
\hline 6 & $\gamma$-CDP (25) & 300 & 5 & 1 & 58 & $6.9 \pm 0.3$ \\
\hline 7 & $\alpha-\operatorname{CDP}(50)$ & 300 & 5 & 1 & 62 & $10.9 \pm 0.4$ \\
\hline 8 & $\beta$-CDP (50) & 300 & 5 & 1 & 55 & $4.3 \pm 0.3$ \\
\hline 9 & $\gamma$-CDP (50) & 300 & 5 & 1 & 58 & $6.6 \pm 0.4$ \\
\hline 10 & $\alpha$-CDP (100) & 300 & 5 & 1 & 63 & $16.7 \pm 0.4$ \\
\hline 11 & $\beta$-CDP (100) & 300 & 5 & 1 & 64 & $10.1 \pm 0.3$ \\
\hline 12 & $\gamma$-CDP (100) & 300 & 5 & 1 & 61 & $9.6 \pm 0.4$ \\
\hline 13 & $\alpha-\mathrm{CDP}(200)$ & 300 & 5 & 1 & 70 & $10.1 \pm 0.3$ \\
\hline 14 & $\beta$-CDP (200) & 300 & 5 & 1 & 66 & $11.2 \pm 0.3$ \\
\hline 15 & $\gamma$-CDP (200) & 300 & 5 & 1 & 62 & $12.5 \pm 0.3$ \\
\hline 16 & $\alpha-\operatorname{CDP}(300)$ & 300 & 5 & 1 & 67 & $12.6 \pm 0.3$ \\
\hline 17 & $\beta$-CDP (300) & 300 & 5 & 1 & 71 & $8.4 \pm 0.3$ \\
\hline 18 & $\gamma-\mathrm{CDP}(300)$ & 300 & 5 & 1 & 72 & $11.9 \pm 0.3$ \\
\hline 19 & $\alpha-\operatorname{CDP}(200)$ & 200 & 5 & 1 & 78 & $20.5 \pm 0.4$ \\
\hline 20 & $\beta$-CDP (200) & 200 & 5 & 1 & 69 & $7.3 \pm 0.3$ \\
\hline 21 & $\gamma$-CDP (200) & 200 & 5 & 1 & 67 & $11.7 \pm 0.5$ \\
\hline 22 & $\alpha$-CDP (200) & 100 & 5 & 1 & 77 & $20.4 \pm 0.4$ \\
\hline Origir & $\mathrm{R}_{\mathrm{F}}-\left(\mathrm{VM}-\mathrm{SiO}_{2}\right)_{i}$ & ${ }_{F}$ nanoparticle & & & & $27.7 \pm 6.7 \mathrm{~nm}^{\mathrm{c})}$ \\
\hline & Original $\alpha$ - & & & & & $15.8 \pm 0.2 \mu \mathrm{m}^{\mathrm{b})}$ \\
\hline & $\beta$-CDP & & & & & $16.6 \pm 0.3 \mu \mathrm{m}^{\mathrm{b})}$ \\
\hline & $\gamma$-CDP & & & & & $17.1 \pm 0.4 \mu \mathrm{m}^{\mathrm{b})}$ \\
\hline
\end{tabular}

a) Yields are based on $\mathrm{R}_{\mathrm{F}}-\left(\mathrm{VM}-\mathrm{SiO}_{2}\right)_{n}-\mathrm{R}_{\mathrm{F}}$ oligomer and $\mathrm{CDPs}$; b) Determined by laser diffraction particle size analyzer in methanol; c) Determined by dynamic light scattering (DLS) measurements in methanol.

$5 \mathrm{ml}$ of $0.1 \%$ methanol solution containing VOCs (concentration of each VOC: $100 \mu \mathrm{g} / \mathrm{dm}^{3}$ ) was poured into the solid-phase extraction cartridge connected with the polyethylene frit containing the $\mathrm{R}_{\mathrm{F}}-\left(\mathrm{CH}_{2} \mathrm{CHSiO}_{2}\right)_{n}-\mathrm{R}_{\mathrm{F}} / \mathrm{CDPs}$ composite powders $(20 \mathrm{mg})$, and the eluent thus obtained was added into the head space vial. Head space operating conditions were $30 \mathrm{~min}$ for sample equilibration at a temperature of $60^{\circ} \mathrm{C}$, and successively subjected to analysis by head space gas chromatography/mass spectrometer (conditions: capillary column: Aquatic $^{\mathrm{TR}}$ : $0.25 \mathrm{~mm}$ I.D. $=60 \mathrm{~m} \mathrm{df}=1.4 \mu \mathrm{m}$; inlet temperature: $200^{\circ} \mathrm{C}$; injection 
volume: $2 \mathrm{ml}$; carrier gas: Helium; column oven temperature: from $40^{\circ} \mathrm{C}$ to $200^{\circ} \mathrm{C}$ (programming rate: $10^{\circ} \mathrm{C} / \mathrm{min}$ ); ion source temperature: $200^{\circ} \mathrm{C}$; ionization energy: $70 \mathrm{eV}$ ). The adsorption ratios (\%) of VOCs were determined based on the calibration curve created by using the corresponding pristine VOCs having known concentrations. Schematic outline for the analytical measurements of the adsorption ratios of the VOCs is illustrated in Scheme 4.

\section{Results and Discussion}

\section{1) Preparation of $\mathrm{R}_{\mathrm{F}}-\left(\mathrm{VM}-\mathrm{SiO}_{2}\right)_{n}-\mathrm{R}_{\mathrm{F}} / \alpha-, \beta-, \gamma$-CDPs composites}

Fluoroalkyl end-capped vinyltrimethoxysilane oligomer $\left[\mathrm{R}_{\mathrm{F}}-\left(\mathrm{CH}_{2} \mathrm{CHSi}(\mathrm{OMe})_{3}\right)_{n}-\mathrm{R}_{\mathrm{F}}: n=2,3 ; \mathrm{R}_{\mathrm{F}}=\mathrm{CF}\left(\mathrm{CF}_{3}\right) \mathrm{OC}_{3} \mathrm{~F}_{7}: \mathrm{R}_{\mathrm{F}}-(\mathrm{VM})_{n}-\mathrm{R}_{\mathrm{F}}\right]$ was found to cause the sol-gel reaction under alkaline conditions in the presence of $\alpha-, \beta-, \gamma$-CDPs at room temperature to provide the corresponding fluorinated oligomeric silica/ $\alpha$-, $\beta$-, $\gamma$-CDPs composites. The results are shown in Scheme 1 and Table 1.

As shown in Scheme 1 and Table 1, the expected composites $\left[\mathrm{R}_{\mathrm{F}}-\left(\mathrm{VM}-\mathrm{SiO}_{2}\right)_{n}-\mathrm{R}_{\mathrm{F}} / \alpha-, \beta-\gamma\right.$-CDPs] were obtained as $38 \%-78 \%$ isolated yields through the sol-gel reaction of the $\mathrm{R}_{\mathrm{F}}-(\mathrm{VM})_{n}-\mathrm{R}_{\mathrm{F}}$ oligomer in the presence of CDPs under alkaline conditions. Table 1 shows that the yields of the composites are sensitive to the feed ratios of CDPs and $\mathrm{R}_{\mathrm{F}}-(\mathrm{VM})_{n}-\mathrm{R}_{\mathrm{F}}$ oligomer employed, increasing with greater feed ratios of CDPs in the oligomer-CDPs. In addition, the size of the composites was found to increase with the increase of the feed ratios of CDPs. These findings would be due to the presence of micrometer-size controlled CDPs particles.

The pristine CDPs have no solubility toward both water and fluorinated aliphatic solvents [1:1 mixed solvents $\left(\mathrm{AK}-225^{\mathrm{TR}}\right)$ of 1, 1-dichloro-2, 2, 3, 3, 3-pentafluoropropane and 1, 3-dichloro-1, 2, 2, 3, 3-pentafluoropropane]; however, the CDPs have a dispersibility toward not only water but also some organic solvents such as dimethyl sulfoxide (DMSO), 1,2-dichloroethane and $N$. $\mathrm{N}$-dimethylformamide (DMF). On the other hand, the fluorinated composites in Table 1 were found to give an extremely poor dispersibility in water; however, these composites afforded good dispersibility and stability in traditional organic media such as tetrahydrofuran, DMSO, 1,2-dichloroethane, DMF, methanol, and 2-propanol including fluorinated aliphatic solvents: AK- $225^{\mathrm{TR}}$. Such dispersibility toward the fluorinated composites; that is, no dispersibility toward water and a good dispersibility toward fluorinated aliphatic solvents, quite different from the pristine CDPs, would be due to the presence of the fluoroalkyl segments in the composites illustrated in Scheme 1.

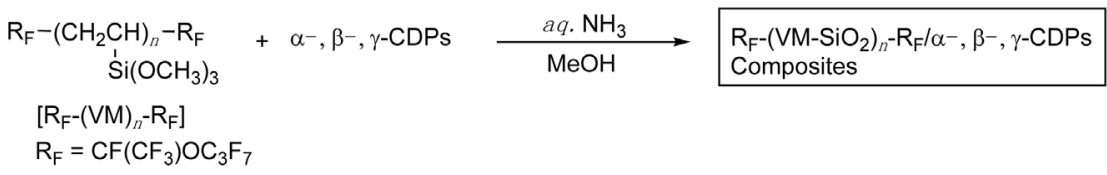

Scheme 1. Preparation of $\mathrm{R}_{\mathrm{F}}-\left(\mathrm{VM}-\mathrm{SiO}_{2}\right)_{n}-\mathrm{R}_{\mathrm{F}} / \alpha-, \beta-, \gamma$-CDPs composites. 
The sizes of the composites in methanol were measured by laser diffraction particle analyzer at $25^{\circ} \mathrm{C}$ (Table 1). Each size of these fluorinated composites is micrometer size-controlled fine particles: $3-17 \mu \mathrm{m}$ as shown in Table 1, on the contrary, the size of the pristine CDPs is $16-17 \mu \mathrm{m}$ levels. The decrease of the size of the obtained composites, compared to that of the pristine CDPs would be due to the agglomeration and aggregation of the pristine CDPs.

In order to clarify the morphology of the obtained composites, FE-SEM photograph of the $\mathrm{R}_{\mathrm{F}}-\left(\mathrm{VM}-\mathrm{SiO}_{2}\right)_{n}-\mathrm{R}_{\mathrm{F}} / \mathrm{CDPs}$ composite powders(Runs 16,17 and 18 in Table 1) was recorded. The FE-SEM measurements of pristine CDPs particle powders and $\mathrm{R}_{\mathrm{F}}-\left(\mathrm{VM}-\mathrm{SiO}_{2}\right)_{n}-\mathrm{R}_{\mathrm{F}}$ oligomeric nanoparticle powders, which were prepared under alkaline conditions, were also measured under similar conditions, for comparison. The results are shown in Figures 1-3.

Figure 1 shows that the pristine $\alpha-, \beta-, \gamma$-CDPs particles are irregular in size, and FE-SEM picture of the $\mathrm{R}_{\mathrm{F}}-\left(\mathrm{VM}-\mathrm{SiO}_{2}\right)_{n}-\mathrm{R}_{\mathrm{F}}$ oligomeric particle powders shows the formation of nanometer size-controlled fine particles (see Figure 2).

In contrast, electron micrographs of our present $\mathrm{R}_{\mathrm{F}}-\left(\mathrm{VM}-\mathrm{SiO}_{2}\right)_{n}-\mathrm{R}_{\mathrm{F}} / \alpha-\mathrm{CDP}$, $\mid \beta$-CDP, and $/ \gamma$-CDP composites show that the $\mathrm{R}_{\mathrm{F}}-\left(\mathrm{VM}-\mathrm{SiO}_{2}\right)_{n}-\mathrm{R}_{\mathrm{F}}$ oligomeric nanoparticles are uniformly coated on each CDP particle surface to provide the corresponding fluorinated oligomeric silica/CDPs composites.

In order to verify the presence of the $\mathrm{R}_{\mathrm{F}}-\left(\mathrm{VM}-\mathrm{SiO}_{2}\right)_{n}-\mathrm{R}_{\mathrm{F}}$ oligomeric nanoparticles in the composites, thermal stability of the fluorinated composites in Table 1 was studied by thermogravimetic analyses, in which the weight loss of these composites was measured by raising the temperature around $800^{\circ} \mathrm{C}$ (the heating rate: $10^{\circ} \mathrm{C} \mathrm{min}{ }^{-1}$ ) in air atmosphere, and the results were shown in Figures 4-6.
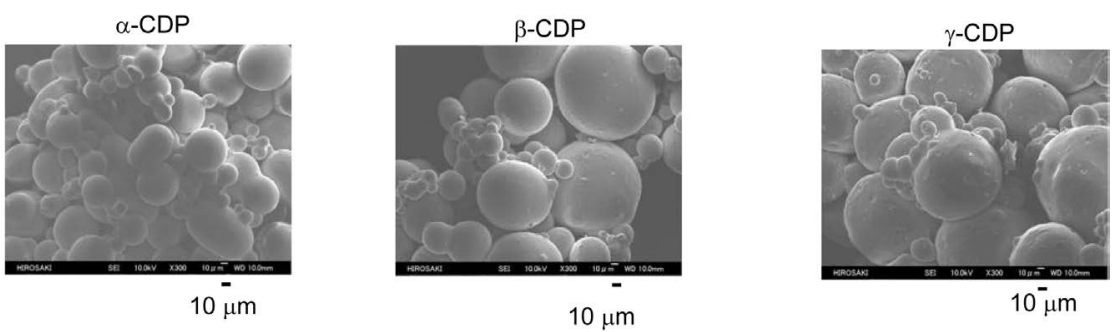

Figure 1. Field emission scanning electron microscopy (FE-SEM) image of pristine $\alpha$-CDP, $\beta$-CDP and $\gamma$-CDP powders.

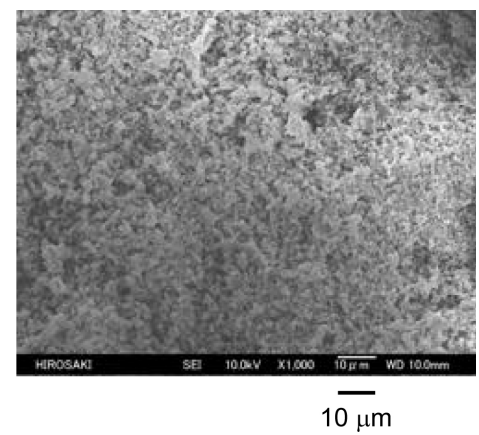

Figure 2. FE-SEM image of the pristine $\mathrm{R}_{\mathrm{F}}-\left(\mathrm{VM}-\mathrm{SiO}_{2}\right)_{n}-\mathrm{R}_{\mathrm{F}}$ nanoparticle powders. 


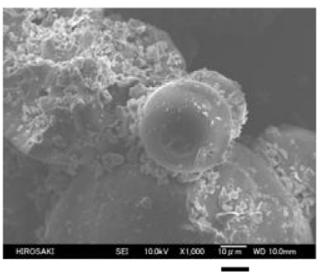

$10 \mu \mathrm{m}$

$\mathrm{R}_{\mathrm{F}}-\left(\mathrm{VM}-\mathrm{SiO}_{2}\right)_{n}-\mathrm{R}_{\mathrm{F}} / \alpha-\mathrm{CDPs}$ composites (Run 16 in Table 1)

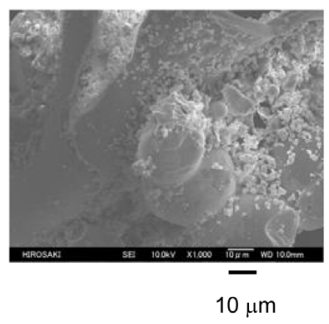

$\mathrm{R}_{\mathrm{F}}-\left(\mathrm{VM}-\mathrm{SiO}_{2}\right)_{n}-\mathrm{R}_{\mathrm{F}} / \beta^{-} \mathrm{CDPS}$ composites (Run 17 in Table 1)

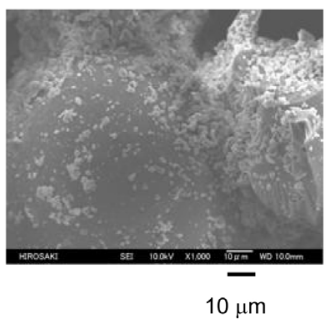

$\mathrm{R}_{\mathrm{F}}-\left(\mathrm{VM}-\mathrm{SiO}_{2}\right)_{\mathrm{n}}-\mathrm{R}_{\mathrm{F}} / \gamma-\mathrm{CDPs}$ composites (Runn 18 in Table 1)

Figure 3. FE-SEM images of $\mathrm{R}_{\mathrm{F}}-\left(\mathrm{VM}-\mathrm{SiO}_{2}\right)_{n}-\mathrm{R}_{\mathrm{F}} / \alpha-, \beta-, \gamma$-CDPs composite powders.

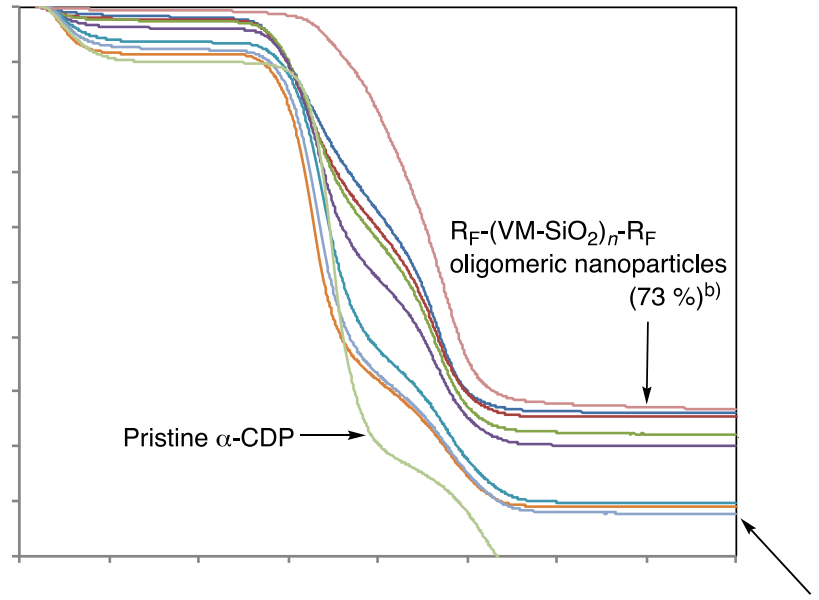

Figure 4. Thermogravimetric analyses of $\mathrm{R}_{\mathrm{F}}-\left(\mathrm{VM}-\mathrm{SiO}_{2}\right)_{n}-\mathrm{R}_{\mathrm{F}} / \alpha$-CDP composites. a) Run No corresponds to that of Table 1 ; b) Weight loss (\%) at $800^{\circ} \mathrm{C}$.

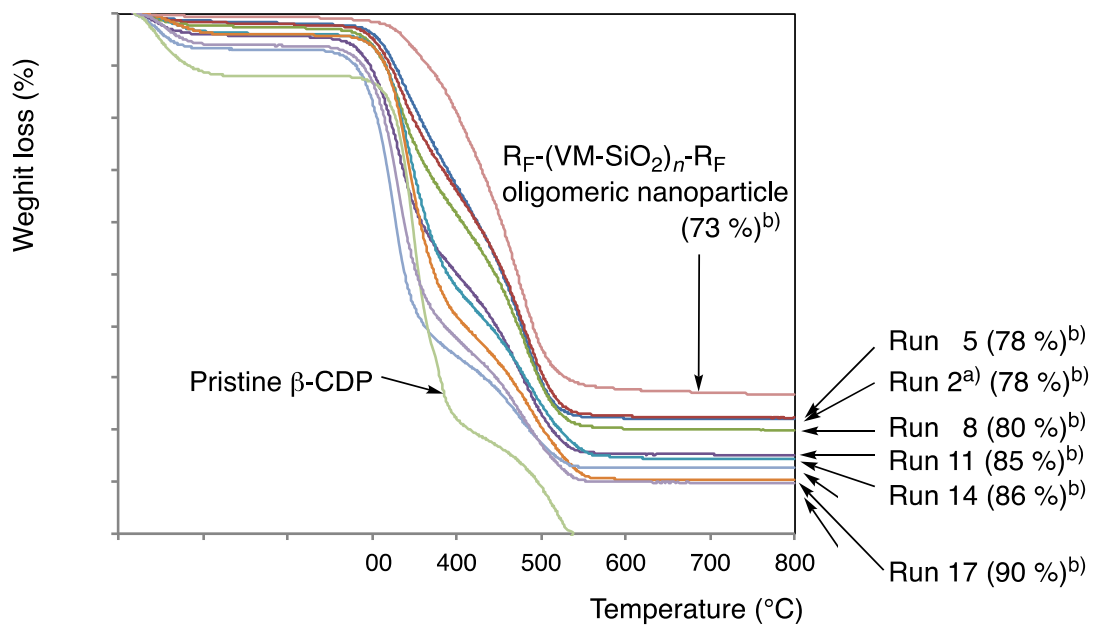

Figure 5. Thermogravimetric analyses of $\mathrm{R}_{\mathrm{F}}-\left(\mathrm{VM}-\mathrm{SiO}_{2}\right)_{n}-\mathrm{R}_{\mathrm{F}} / \beta$-CDP composites. a) Run No corresponds to that of Table 1 ; b) Weight loss (\%) at $800^{\circ} \mathrm{C}$.

As shown in Figure 4, the pristine $\mathrm{R}_{\mathrm{F}}-\left(\mathrm{VM}-\mathrm{SiO}_{2}\right)_{n}-\mathrm{R}_{\mathrm{F}}$ oligomeric nanoparticles, which were prepared by the sol-gel reaction of $\mathrm{R}_{\mathrm{F}}-(\mathrm{VM})_{n}-\mathrm{R}_{\mathrm{F}}$ oligomer under 


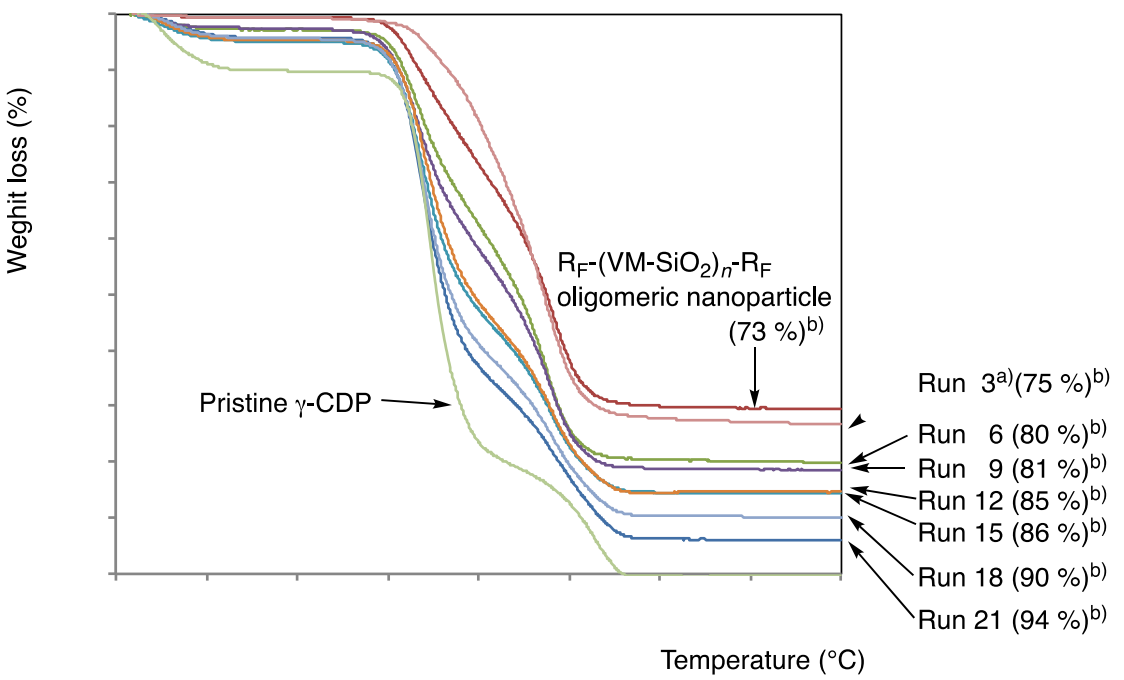

Figure 6. Thermogravimetric analyses of $\mathrm{R}_{\mathrm{F}}-\left(\mathrm{VM}-\mathrm{SiO}_{2}\right)_{n}-\mathrm{R}_{\mathrm{F}} / \gamma-\mathrm{CDP}$ composites. a) Run No corresponds to that of Table 1 ; b) Weight loss (\%) at $800^{\circ} \mathrm{C}$.

alkaline conditions in Scheme 1, afforded the $73 \%$ weight loss around at $530^{\circ} \mathrm{C}$, owing to the partial formation of silica gel during the calcination process. Pristine $\alpha$-CDP afforded a perfect weight loss at around $540^{\circ} \mathrm{C}$. In contrast, the $\mathrm{R}_{\mathrm{F}}-\left(\mathrm{VM}-\mathrm{SiO}_{2}\right)_{n}-\mathrm{R}_{\mathrm{F}} / \alpha$-CDP composites (Runs $1,4,7,10,13$ and 16 in Table 1 ) were found to provide the weight loss behavior in proportion to the contents of the $\mathrm{R}_{\mathrm{F}}-\left(\mathrm{VM}-\mathrm{SiO}_{2}\right)_{n}-\mathrm{R}_{\mathrm{F}}$ oligomeric nanoparticles in the composites after calcination at $800^{\circ} \mathrm{C}$, and the contents of $\alpha$-CDP in the composites were estimated to be from $1 \%$ to $19 \%$. Similar TGA curves for the $\mathrm{R}_{\mathrm{F}}-\left(\mathrm{VM}-\mathrm{SiO}_{2}\right)_{n}-\mathrm{R}_{\mathrm{F}} / \beta$-CDP and $/ \gamma$-CDP composites were observed, and the contents of $\beta$-CDP and $\gamma$-CDP in the $\mathrm{R}_{\mathrm{F}}-\left(\mathrm{VM}-\mathrm{SiO}_{2}\right)_{n}-\mathrm{R}_{\mathrm{F}}$ composites were also estimated under similar conditions. The results are as follows:

\begin{tabular}{lcccccccc}
\hline \multicolumn{7}{c}{ Contents (\%) of CDPs in the composites: } \\
\hline$\alpha$-CDP & Run 1 & Run 4 & Run 7 & Run 10 & Run 13 & Run 16 & Run 19 & \\
& 1 & 2 & 5 & 7 & 17 & 18 & 19 & \\
$\beta$-CDP & Run 2 & Run 5 & Run 8 & Run 11 & Run 14 & Run 17 & Run 20 & Run 22 \\
& 5 & 5 & 7 & 12 & 13 & 17 & 17 & 14 \\
$\gamma$-CDP & Run 3 & Run 6 & Run 9 & Run 12 & Run 15 & Run 18 & Run 21 & \\
& 2 & 7 & 8 & 12 & 13 & 17 & 21 & \\
\hline
\end{tabular}

The contents of CDPs in the obtained composites were found to increase from $1 \%$ - $5 \%$ to $17 \%$ - $18 \%$ with increasing the feed ratios of CDPs in the CDPs-oligomer $(300 \mathrm{mg}$ ) from 10 to $300 \mathrm{mg}$ in the composites reactions (illustrated in Scheme $1)$.

\section{2) Surface property of $\mathrm{R}_{\mathrm{F}}-\left(\mathrm{VM}-\mathrm{SiO}_{2}\right)_{n}-\mathrm{R}_{\mathrm{F}} / \mathrm{CDPs}$ composites}

In order to clarify the surface active characteristics of the present composites in Table 1, these fluorinated composites have been applied to the surface mod- 
ification of glass, and we have measured the dodecane and water contact angle values on these modified glass surfaces. The results are shown in Table 2.

It is well known that $\mathrm{R}_{\mathrm{F}}-\left(\mathrm{CH}_{2} \mathrm{CHSi}(\mathrm{OMe})_{3}\right)_{n}-\mathrm{R}_{\mathrm{F}}$ oligomer can undergo the sol-gel reaction to afford the corresponding fluoroalkyl end-capped oligomeric silica nanoparticles $\left[\mathrm{R}_{\mathrm{F}}-\left(\mathrm{CH}_{2} \mathrm{CHSiO}_{2}\right)_{n}-\mathrm{R}_{\mathrm{F}}\right][20] . \mathrm{R}_{\mathrm{F}}-\left(\mathrm{CH}_{2} \mathrm{CHSiO}_{2}\right)_{n}-\mathrm{R}_{\mathrm{F}}$ oligomeric nanoparticles thus obtained were also applied to the surface modification to provide an oleophobic/superhydrophobic characteristic on the modified glass surface [20]. In fact, as shown in Table 2, the dodecane and water contact angle values on the modified glass surface treated with the $\mathrm{R}_{\mathrm{F}}-\left(\mathrm{CH}_{2} \mathrm{CHSiO}_{2}\right)_{n}-\mathrm{R}_{\mathrm{F}}$ oligomeric nanoparticles are 48 and 180 degrees to exhibit the oleophobic and superhydrophobic characteristic. However, interestingly, it was demonstrated that the $\mathrm{R}_{\mathrm{F}}-\left(\mathrm{CH}_{2} \mathrm{CHSiO}_{2}\right)_{n}-\mathrm{R}_{\mathrm{F}} / \mathrm{CDPs}$ composites illustrated in Table 2 can afford a superoleophilic/superhydrophobic characteristic; because the dodecane and water contact angle values are 0 and 180 degrees in each case, although each composite contains the longer fluoroalkyl groups possessing a good oleophobic property.

There have been heretofore a variety of reports on the creation of the superoleophilic/superhydrophobic surface through the architecture of the roughness surfaceby using a variety of methods, such as a porous film formation composed of poly (tetrafluoroethylene) nanoparticles [24], spray coating with hydrophobic silica nanoparticles suspension [25], the treatment with a mixture of hydrophobic silica nanoparticles and polystyrene solution in toluene [26]. Especially, the introduction of a proper rough surface microstructure should make a flat hydrophobic surface superhydrophobic, owing to the introduction of an air cushion beneath the water droplet; in contrast, a flat oleophilic surface should become superoleophilic through the capillary effect [27]-[35]. Thus, in order to verify such unique surface wettability, we tried to study on the surface roughness of the modified glass surface by the treatments of the $\mathrm{R}_{\mathrm{F}}-\left(\mathrm{CH}_{2} \mathrm{CHSiO}_{2}\right)_{n}-\mathrm{R}_{\mathrm{F}} / \alpha$-CDP composites (Run 16 in Table 1) by FE-SEM measurements and dynamic force microscopy (DFM) measurements. The modified glass surface treated with the

Table 2. Contact angles of dodecane and water on the modified glasses treated with the $\mathrm{R}_{\mathrm{F}}-\left(\mathrm{VM}-\mathrm{SiO}_{2}\right)_{n}-\mathrm{R}_{\mathrm{F}} / \mathrm{CDPs}$ composites.

Dodecane (degree) Water(degree)

$\mathrm{R}_{\mathrm{F}}-\left(\mathrm{VM}-\mathrm{SiO}_{2}\right)_{n}-\mathrm{R}_{\mathrm{F}} / \alpha$-CDP composites (Runs $1,4,7,10,13,16$ and 19)*

$\mathrm{R}_{\mathrm{F}}-\left(\mathrm{VM}-\mathrm{SiO}_{2}\right)_{n}-\mathrm{R}_{\mathrm{F}} / \beta$-CDP composites

(Runs 2, 5, 8, 11, 14, 17, 20 and 22)

$\mathrm{R}_{\mathrm{F}}-\left(\mathrm{VM}-\mathrm{SiO}_{2}\right)_{n}-\mathrm{R}_{\mathrm{F}} / \gamma$-CDP composites (Runs 3, 6, 9, 12, 15, 18 and 21)

$\mathrm{R}_{\mathrm{F}}-\left(\mathrm{VM}-\mathrm{SiO}_{2}\right)_{n}-\mathrm{R}_{\mathrm{F}}$ oligomeric nanoparticles

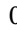

48
180

180

180

180

*) Each Run No. corresponds to that of Table 1. 
$\mathrm{R}_{\mathrm{F}}-\left(\mathrm{CH}_{2} \mathrm{CHSiO}_{2}\right)_{\mathrm{n}}-\mathrm{R}_{\mathrm{F}}$ oligomeric nanoparticles were also studied under similar conditions, for comparison. The results are shown in Figure 7.

As shown in Figure 7(a), we have observed the architecture of the effective roughness surface on the modified glass surface, compared with that (Figure $7(b)$ ) of the modified glass surface treated with the $\left.\mathrm{R}_{\mathrm{F}}-\left(\mathrm{CH}_{2} \mathrm{CHSiO}\right)_{2}\right)_{\mathrm{n}}-\mathrm{R}_{\mathrm{F}}$ oligomeric nanoparticles. Especially, the topographical image of the modified surface treated with the $\mathrm{R}_{\mathrm{F}}-\left(\mathrm{CH}_{2} \mathrm{CHSiO}_{2}\right)_{\mathrm{n}}-\mathrm{R}_{\mathrm{F}} / \alpha$-CDP composites afforded an effective roughness characteristic, and we can observe a higher roughness average values: $\mathrm{Ra}: 111 \mathrm{~nm}$ than that (Ra: $7 \mathrm{~nm}$ ) of the pristine $\mathrm{R}_{\mathrm{F}}-\left(\mathrm{CH}_{2} \mathrm{CHSiO}_{2}\right)_{\mathrm{n}}-\mathrm{R}_{\mathrm{F}}$ oligomeric nanoparticles. Such higher roughness value is due to the presence of micrometer size-controlled $\alpha$-CDP particles in the composites, providing a superoleophilic/superhydrophobic characteristic on the modified surface. Similar higher roughness values $(\mathrm{Ra}): 135 \mathrm{~nm}$ and $82 \mathrm{~nm}$ were obtained on the modified glass surfaces treated with the $\mathrm{R}_{\mathrm{F}}-\left(\mathrm{CH}_{2} \mathrm{CHSiO}_{2}\right)_{\mathrm{n}}-\mathrm{R}_{\mathrm{F}} / \beta$-CDP composites (Run 17 in Table 1) and the $\mathrm{R}_{\mathrm{F}}-\left(\mathrm{CH}_{2} \mathrm{CHSiO}_{2}\right)_{n}-\mathrm{R}_{\mathrm{F}} / \gamma-\mathrm{CDP}$ composites (Run 18 in Table 1), respectively (data not shown). Such higher roughness surfaces would interact with oil (dodecane) possessing the lower surface tension than that of water to

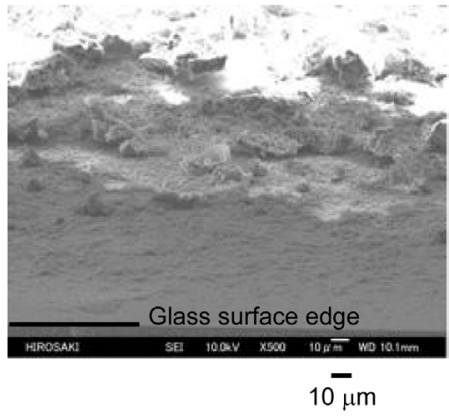

(a)

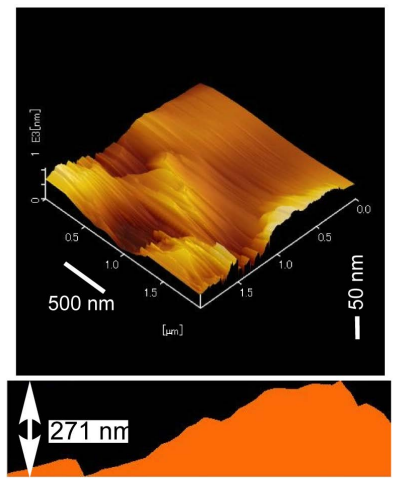

$\mathrm{R}_{\mathrm{F}}-\left(\mathrm{VM}-\mathrm{SiO}_{2}\right)_{n}-\mathrm{R}_{\mathrm{F}} / \alpha-\mathrm{CDP}$ composites $\mathrm{R}_{\mathrm{F}}-\left(\mathrm{VM}-\mathrm{SiO}_{2}\right)_{n}-\mathrm{R}_{\mathrm{F}}$ oligomeric nanoparticles Ra: $111 \mathrm{~nm}$

(c)

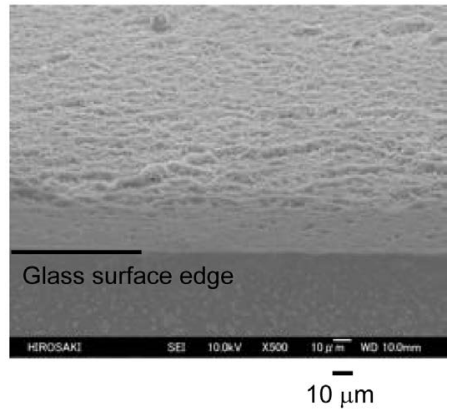

(b)
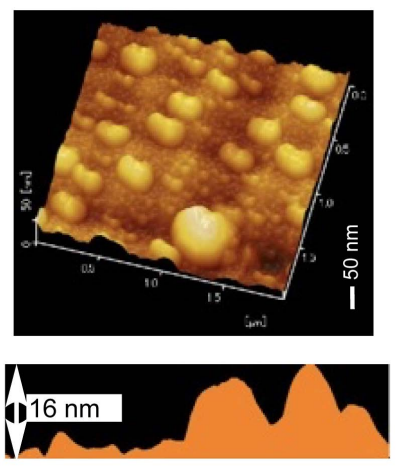

(d)

Figure 7. FE-SEM (Field Emission Scanning Electron Microscopy) images of the modified glass surface treated with the $\mathrm{R}_{\mathrm{F}}-\left(\mathrm{VM}-\mathrm{SiO}_{2}\right)_{n}-\mathrm{R}_{\mathrm{F}} / \alpha$-CDP composites (a), the $\mathrm{R}_{\mathrm{F}}-\left(\mathrm{VM}-\mathrm{SiO}_{2}\right)_{n}-\mathrm{R}_{\mathrm{F}}$ nanoparticles (b); and DFM (Dynamic Force Microscopy) topographic images of the modified glass surface treated with the $\mathrm{R}_{\mathrm{F}}-\left(\mathrm{VM}-\mathrm{SiO}_{2}\right)_{n}-\mathrm{R}_{\mathrm{F}} / \alpha$-CDP composites (c); the $\mathrm{R}_{\mathrm{F}}-\left(\mathrm{VM}-\mathrm{SiO}_{2}\right)_{n}-\mathrm{R}_{\mathrm{F}}$ nanoparticles (d). 
give the superoleophilic characteristic, because an oil droplet could easily penetrate the very small orifice between the microsize-controlled composites particles. In contrast, the fluoroalkyl segments in the composites can be arranged on the modified roughness surface to afford the superhydrophobic characteristic.

3) Application of $\mathrm{R}_{\mathrm{F}}-\left(\mathrm{VM}-\mathrm{SiO}_{2}\right)_{n}-\mathrm{R}_{\mathrm{F}} / \mathrm{CDPs}$ composites to the separation of the mixture of oil and water

In this way, it was demonstrated that our present fluorinated composites can provide a superoleophilic/superhydrophobic property. The superoleophilic surface possesses in general a strong affinity toward oils. Therefore, the surfaces having the superoleophilic/superhydrophobic characteristic can simultaneously repels water and strongly absorbs oils, of whose behavior should be applicable to the separation of oil and water [36] [37] [38] [39]. Thus, we tried to separate three kinds of mixtures of oil and water such as the $\mathrm{O} / \mathrm{W}$ emulsions (oils: 1,2-dichloroethane and toluene) and the mixture of water [5 $\mathrm{ml}$ : water was colored with $\left.\mathrm{CuSO}_{4} 5 \mathrm{H}_{2} \mathrm{O}(200 \mathrm{mg})\right]$ and 1,2-dichloroethane $(5 \mathrm{ml})$. The traditional silica-gel (Wakogel ${ }^{\mathrm{TR}} \mathrm{C}-500 \mathrm{HG}$ : average particle size: $21 \mu \mathrm{m}$ ) was not effective for the packing material for column chromatography to separate these mixtures under reduced pressure. However, interestingly, we can isolate the only transparent colorless oils under similar conditions by using the $\mathrm{R}_{\mathrm{F}}-\left(\mathrm{CH}_{2} \mathrm{CHSiO}_{2}\right)_{n}-\mathrm{R}_{\mathrm{F}} / \mathrm{CDPs}$ composite powders as the packing materials for column chromatography. The recovery ratios $\left(w / w_{0}\right)$ ( $w$. weight of the isolated transparent colorless oil; $w_{0}$ : weight of the used oil) of the isolated transparent colorless oils from the mixtures of oil and water are shown in Table 3.

As shown in Table 3, the $\mathrm{R}_{\mathrm{F}}-\left(\mathrm{CH}_{2} \mathrm{CHSiO}_{2}\right)_{n}-\mathrm{R}_{\mathrm{F}} / \alpha$-, $\beta$-, $\gamma$-CDPs composites (Runs 1, 2 and 3), which were prepared under the feed ratios of CDPs/oligomer: $10 / 300$, were found to provide a similarly good recovery ratios to those of the

Table 3. Recovery ratios of oils from the mixtures of oils and water by using the $\mathrm{R}_{\mathrm{F}}-\left(\mathrm{CH}_{2} \mathrm{CHSiO}_{2}\right)_{n}-\mathrm{R}_{\mathrm{F}} / \mathrm{CDPs}$ composites as the packing materials for column chromatography.

\begin{tabular}{cccc}
\hline & \multicolumn{3}{c}{ Recovery ratio (\%) } \\
\cline { 2 - 4 } Composites & \begin{tabular}{c} 
Mixture of $\begin{array}{c}1,2 \text {-dichloroethane } \\
\text { and water }\end{array}$ \\
\cline { 2 - 3 }
\end{tabular} $\mathrm{R}_{\mathrm{F}}-\left(\mathrm{CH}_{2} \mathrm{CHSiO}_{2}\right)_{n}-\mathrm{R}_{\mathrm{F}} / \alpha$-CDP composites \\
Run 1 & 80 & 82 & oil: toluene \\
Run 16 & 73 & 75 & 82 \\
& $\mathrm{R}_{\mathrm{F}}-\left(\mathrm{CH}_{2} \mathrm{CHSiO}_{2}\right)_{n}-\mathrm{R}_{\mathrm{F}} / \beta$-CDP composites & 79 \\
Run 2 & 67 & 78 & 76 \\
Run 17 & 70 & 81 & 81 \\
& $\mathrm{R}_{\mathrm{F}}-\left(\mathrm{CH}_{2} \mathrm{CHSiO}_{2}\right)_{n}-\mathrm{R}_{\mathrm{F}} / \gamma$-CDP composites & \\
Run 3 & 77 & 78 & 77 \\
Run 18 & 77 & 82 & 83 \\
\hline
\end{tabular}

*) Each Run No. corresponds to that of Table 1. 
other fluorinated composites, which were prepared under the feed ratios of CDPs/oligomer: 300/300. This finding would be due to the superoleophilic/superhydrophobic characteristic in each composite illustrated in Table 2, and the composites possessing such wettability can strongly interact with oils in the aqueous solutions to isolate only oils from the mixtures.

4) Adsorption of organic molecules by using the $\mathrm{R}_{\mathrm{F}}-\left(\mathrm{CH}_{2} \mathrm{CHSiO}_{2}\right)_{n}-\mathrm{R}_{\mathrm{F}} / \mathrm{CDPs}$ composites

The traditional organic dyes in many industries such as plastics, textile and cosmetics are in general common water pollutants and we can detect trace quantities in industrial wastewater. Thus, it is very important to develop new technologies to eliminate them [40]. Hitherto, water-insoluble cyclodextrin polymers (CDPs) have been applied for the removal of various organic dyes from aqueous solutions [40]-[46]. From this point of view, it is deeply desirable to develop new CDP derivatives possessing a higher adsorption ability, compared to that of the pristine CDPs. Here our present $\left.\mathrm{R}_{\mathrm{F}}-\left(\mathrm{CH}_{2} \mathrm{CHSiO}\right)_{n}\right)_{n}-\mathrm{R}_{\mathrm{F}} / \mathrm{CDPs}$ composites were investigated for adsorption of aromatic compounds such as bisphenol $\mathrm{A}$ and bisphenol AF in their aqueous methanol solutions. Schematic illustration for the adsorption process of bisphenol A (BPA) or bisphenol AF (BPAF) by using the solid-phase extraction cartridge connected with the polyethylene frit packed with the $\mathrm{R}_{\mathrm{F}}-\left(\mathrm{CH}_{2} \mathrm{CHSiO}_{2}\right)_{n}-\mathrm{R}_{\mathrm{F}} / \mathrm{CDPs}$ composite powders is illustrated in Scheme 2. We have also investigated the adsorption ability of BPA and BPAF by using the pristine CDPs $\left(20 \mathrm{mg} \text { ), and the } \mathrm{R}_{\mathrm{F}}-\left(\mathrm{CH}_{2} \mathrm{CHSiO}\right)_{n}\right)_{n}-\mathrm{R}_{\mathrm{F}} / \mathrm{PTFE}$ (polyterafluoroethylene) composites $(20 \mathrm{mg}$ ) possessing a superoleophilic/superhydrophobic property [22] under similar conditions, for comparison. These results are shown in Table 4.

Table 4. Adsorption ratio (\%) of $\mathrm{BPA}$ and BPAF using the $\mathrm{R}_{\mathrm{F}}-\left(\mathrm{CH}_{2} \mathrm{CHSiO}_{2}\right)_{n}-\mathrm{R}_{\mathrm{F}} / \mathrm{CDPs}$ composites.

\begin{tabular}{cccc}
\hline CDPs in the composites & \multicolumn{2}{c}{ Adsorption ratio (\%) } \\
\hline Run $^{*}$ & $\alpha$-CDP & BPA & BPAF \\
19 & & 47 & 52 \\
10 & $\beta$-CDP & - & 34 \\
& & 100 & 93 \\
20 & $\gamma$-CDP & - & 94 \\
11 & & 58 & 69 \\
21 & & - & 54 \\
12 & & 48 & 61 \\
Pristine $\alpha$-CDP $_{\beta-C D P}$ & 75 & 73 \\
$\gamma$-CDP & 59 & 64 \\
$\mathrm{R}_{\mathrm{F}}-\left(\mathrm{CH}_{2} \mathrm{CHSiO}_{2}\right)_{n}-\mathrm{R}_{\mathrm{F}} / \mathrm{PTFE}^{* *}$ & & - & 5 \\
\hline
\end{tabular}

${ }^{\star}$ Each Run No. corresponds to that of Table $1 ;{ }^{*}$ Preparative feed ratio of PTFE/oligomer (mg/mg): $100 / 300$. 


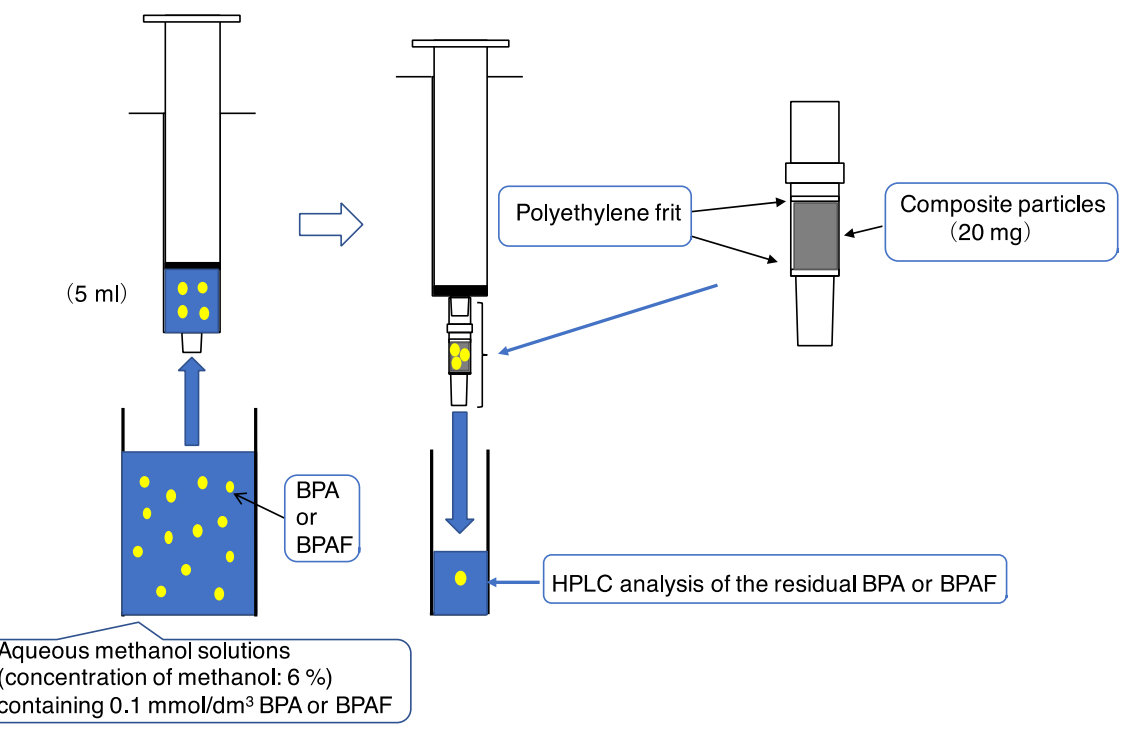

Scheme 2. Schematic outline for the analysis of the adsorption ratios of bisphenol A (BPA) or bisphenol AF (BPAF) by using the solid-phase extraction cartridge connected with the polyethylene frit packed with the $\mathrm{R}_{\mathrm{F}}-\left(\mathrm{CH}_{2} \mathrm{CHSiO}_{2}\right)_{n}-\mathrm{R}_{\mathrm{F}} / \mathrm{CDPs}$ composite powders.

As shown in Table 4, the adsorption ability of BPA and BAPF is sensitive to the structures of CDPs in the $\mathrm{R}_{\mathrm{F}}-\left(\mathrm{CH}_{2} \mathrm{CHSiO}_{2}\right)_{n}-\mathrm{R}_{\mathrm{F}} / \mathrm{CDPs}$ composites, and the highest adsorption ability of BPA or BPAF was observed by the use of the $\beta$-CDP in the composites, respectively. It was also demonstrated that the $\mathrm{R}_{\mathrm{F}}-\left(\mathrm{CH}_{2} \mathrm{CHSiO}_{2}\right)_{n}-\mathrm{R}_{\mathrm{F}} / \beta$-CDP composites can enhance the adsorption ability of BPA and BPAF, effectively than that of the pristine $\beta$-CDP under similar conditions, indicating that since the present $\mathrm{R}_{\mathrm{F}}-\left(\mathrm{CH}_{2} \mathrm{CHSiO}_{2}\right)_{n}-\mathrm{R}_{\mathrm{F}} / \beta-\mathrm{CDP}$ composites can exhibit a superoleophilic characteristic with a superhydrophobic property, such superoleophilic characteristic should interact strongly with oleophilic organic molecules in the aqueous solutions to give a higher adsorption ability; although the pristine $\beta$-CDP cannot possess such higher oleophilic property. Especially, the size-fitness of the interior cavity of $\beta$-CDP (not $\alpha$ - and $\gamma$-CDPs) in the composites toward BPA or BPAF can provide a higher adsorption ability to form the inclusion derivatives with such aromatic compounds. From this finding, it is suggested that the higher adsorption ratios of BPA or BAPF should be much related to the presence of CDPs in the composites. In fact, the $\mathrm{R}_{\mathrm{F}}-\left(\mathrm{CH}_{2} \mathrm{CHSiO}_{2}\right)_{n}-\mathrm{R}_{\mathrm{F}} /$ PTFE composites [22], which can exhibit a similar superoleophilic/superhydrophobic characteristic, were unable to provide the adsorption ability as shown in Table 4.

We tried to study on the reusability of the $\mathrm{R}_{\mathrm{F}}-\left(\mathrm{CH}_{2} \mathrm{CHSiO}_{2}\right)_{n}-\mathrm{R}_{\mathrm{F}} / \beta-\mathrm{CDP}$ composite powders (20 mg: Run 22 in Table 1) as the packing material for the solid-phase extraction cartridge for the adsorption and desorption of BPA. The Schematic outline for the recycling process for the adsorption and desorption of BPA by using the $\mathrm{R}_{\mathrm{F}}-\left(\mathrm{CH}_{2} \mathrm{CHSiO}_{2}\right)_{n}-\mathrm{R}_{\mathrm{F}} / \beta$-CDP composite powders as the packing material is shown in Scheme 3. 


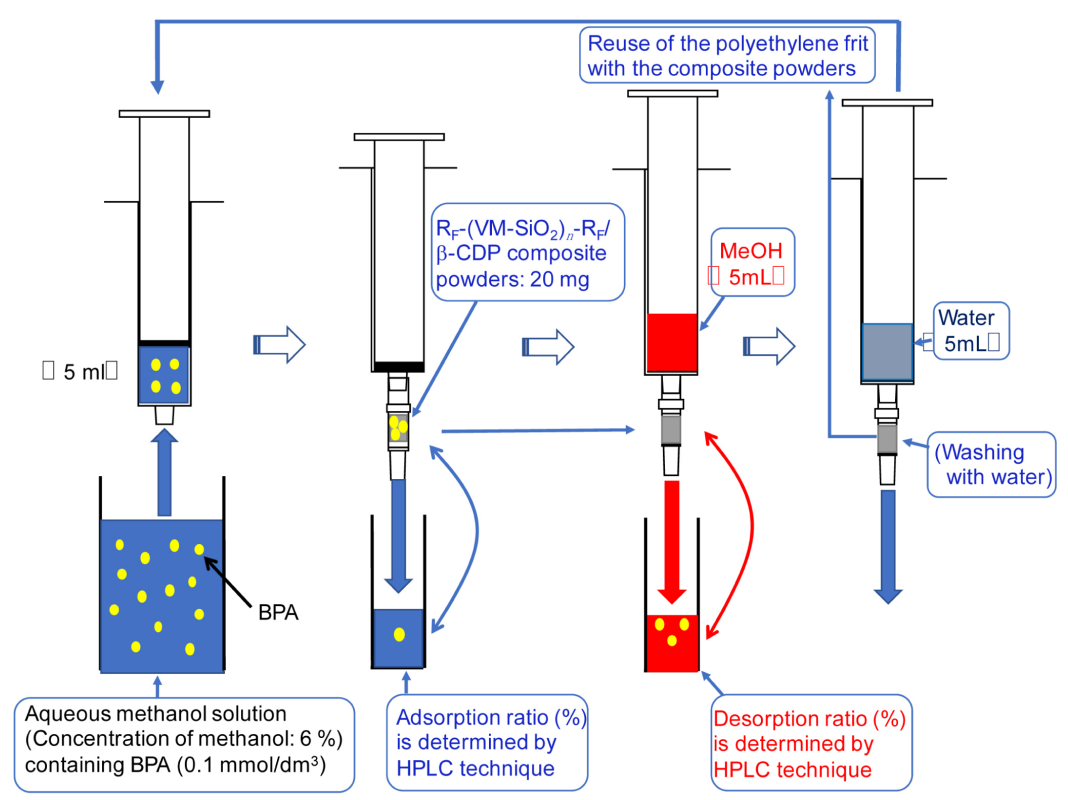

Scheme 3. Schematic outline for the recycling process for the adsorption and desorption of BPA by using the $\mathrm{R}_{\mathrm{F}}-\left(\mathrm{CH}_{2} \mathrm{CHSiO}_{2}\right)_{n}-\mathrm{R}_{\mathrm{F}} / \beta$-CDP composite powders as the packing material.

As shown in Scheme 3 and Figure 8, a good recyclability was observed for the use of the $\mathrm{R}_{\mathrm{F}}-\left(\mathrm{CH}_{2} \mathrm{CHSiO}_{2}\right)_{n}-\mathrm{R}_{\mathrm{F}} / \beta$-CDP composite powders as the packing material for the adsorption and desorption of the BPA even after 10 cycle, and the adsorption and desorption ratios in each cycle are $98 \%-100 \%$ and $69 \%-91 \%$, respectively. In this way, the present $\mathrm{R}_{\mathrm{F}}-\left(\mathrm{CH}_{2} \mathrm{CHSiO}_{2}\right)_{n}-\mathrm{R}_{\mathrm{F}} / \mathrm{CDP}$ composites may be developed as the new adsorbent toward the aromatic molecules in their aqueous solutions, especially, the trace amounts of toxic aromatic compounds in industrial wastewater.

Recently, there is a serious problem in increasing environmental pollution, such as the discharge of the industrial wastewater including volatile organic compounds (VOC) [47] [48]. From this point of view, it is suggested that our present $\mathrm{R}_{\mathrm{F}}-\left(\mathrm{CH}_{2} \mathrm{CHSiO}_{2}\right)_{n}-\mathrm{R}_{\mathrm{F}} / \mathrm{CDPs}$ composites would have high potential for the application of novel adsorbent toward not only aromatic compounds such as BPA but also a variety of VOCs. Thus, the $\mathrm{R}_{\mathrm{F}}-\left(\mathrm{CH}_{2} \mathrm{CHSiO}_{2}\right)_{n}-\mathrm{R}_{\mathrm{F}} / \mathrm{CDPs}$ composites (Runs19, 20 and 21 in Table 1) have been applied to the packing materials for the adsorption of VOCs such as benzene, toluene, xylenes, trichloroethylene, tetrachloroethylene, chloroform, and tetrachlorometane by using the head space-gas chromatograph/mass spectrometer (GC/MS) measurements (the analytical measurement outline: see Scheme 4). The adsorption ability of the VOCs was also studied by using the pristine CDPs under similar conditions, for comparison. The results are shown in Table 5.

As shown in Table 4, the $\mathrm{R}_{\mathrm{F}}-\left(\mathrm{CH}_{2} \mathrm{CHSiO}_{2}\right)_{n}-\mathrm{R}_{\mathrm{F}} / \mathrm{CDPs}$ composites were found to exhibit a higher adsorption ability for VOCs, compared to that of the pristine CDPs. $\mathrm{R}_{\mathrm{F}}-\left(\mathrm{CH}_{2} \mathrm{CHSiO}_{2}\right)_{n}-\mathrm{R}_{\mathrm{F}} / \beta$-CDP composites can possess a higher adsorption ability, quite similar to that of BPA and BPAF illustrated in Table 4. 
Table 5. Adsorption ratios of VOCs by the use of $\mathrm{R}_{\mathrm{F}}-\left(\mathrm{CH}_{2} \mathrm{CHSiO}_{2}\right)_{n}-\mathrm{R}_{\mathrm{F}} / \beta-\mathrm{CDP}$ composites (Run 20 in Table 1).

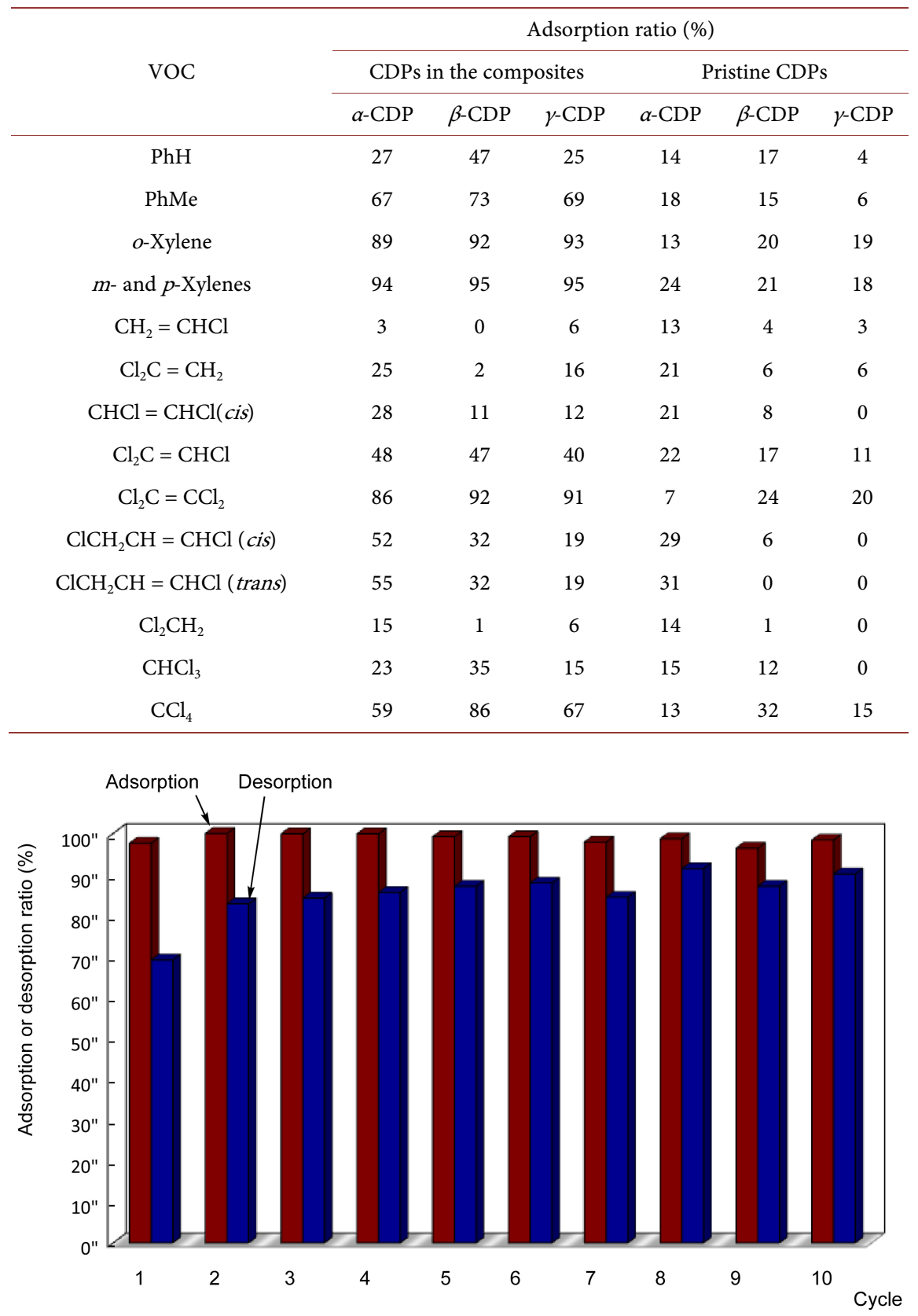

Figure 8. Relationship between the recyclability of the $\mathrm{R}_{\mathrm{F}}-\left(\mathrm{CH}_{2} \mathrm{CHSiO}_{2}\right)_{n}-\mathrm{R}_{\mathrm{F}} / \beta$-CDP composites (Run 22 in Table 1 ) as the packing material, and the adsorption and desorption ratios of $\mathrm{BPA}$ in each cycle

In the adsorption of the mono and di-chlorinated VOCs such as $\mathrm{CH}_{2}=\mathrm{CHCl}$, $\mathrm{Cl}_{2} \mathrm{C}=\mathrm{CH}_{2}, \mathrm{CHCl}=\mathrm{CHCl}$, and $\mathrm{Cl}_{2} \mathrm{CH}_{2}$, the $\mathrm{R}_{\mathrm{F}}-\left(\mathrm{CH}_{2} \mathrm{CHSiO}_{2}\right)_{n}-\mathrm{R}_{\mathrm{F}} / \mathrm{CDPs}$ composites afforded a similar adsorption behavior to that of the pristine CDPs. However, in the cases of the tri- and tetra-chlorinated VOCs such as $\mathrm{Cl}_{2} \mathrm{C}=$ $\mathrm{CHCl}, \mathrm{Cl}_{2} \mathrm{C}=\mathrm{CCl}_{2}, \mathrm{CHCl}_{3}$ and $\mathrm{CCl}_{4}$, interestingly, these VOCs can be easily adsorbed by the $\mathrm{R}_{\mathrm{F}}-\left(\mathrm{CH}_{2} \mathrm{CHSiO}_{2}\right)_{n}-\mathrm{R}_{\mathrm{F}} / \mathrm{CDPs}$ composites, especially by the 


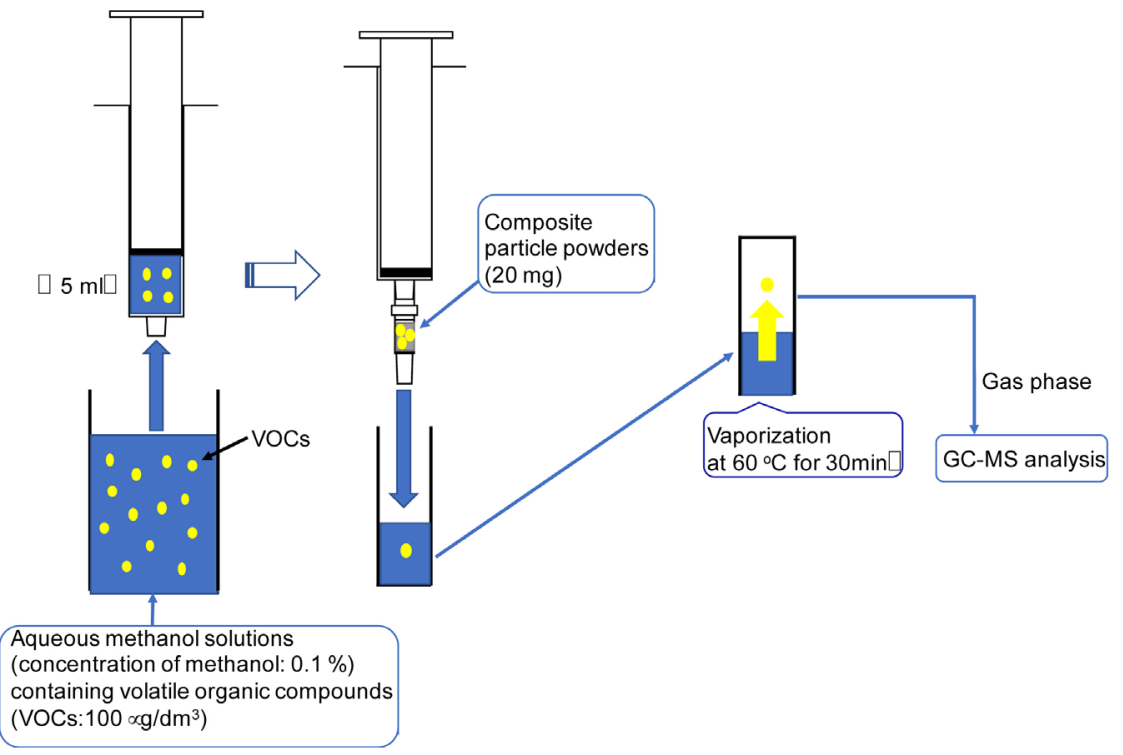

Scheme 4. Schematic outline for the analysis of the adsorption ratios of the VOCs by the head space-GC/MS measurements.

$\mathrm{R}_{\mathrm{F}}-\left(\mathrm{CH}_{2} \mathrm{CHSiO}_{2}\right)_{n}-\mathrm{R}_{\mathrm{F}} / \beta$-CDP composites. These findings would be due to the increase of the oleophilicity of VOCs by introducing the additional chlorine atoms into VOCs; because the $\mathrm{R}_{\mathrm{F}}-\left(\mathrm{CH}_{2} \mathrm{CHSiO}_{2}\right)_{n}-\mathrm{R}_{\mathrm{F}} / \mathrm{CDPs}$ composites can possess a superoleophilic property to interact with more oleophilic organic molecules. On the other hand, dichlorinated VOCs such as $\mathrm{ClCH}_{2} \mathrm{CH}=\mathrm{CHCl}$ (cis and trans) can give a higher adsorption ability than the pristine CDPs, quite different from the similar dichlorinated VOCs such as $\mathrm{CH}_{2}=\mathrm{CHCl}$ and $\mathrm{Cl}_{2} \mathrm{C}=\mathrm{CH}_{2}$. This finding would be due to the longer carbon chains (three carbon chains) to give more oleophilic property.

In the cases of aromatic VOCs such as benzene, toluene, $o$-, $m$-, and $p$-xylenes, these aromatic VOCs are likely to interact with the $\mathrm{R}_{\mathrm{F}}-\left(\mathrm{CH}_{2} \mathrm{CHSiO}_{2}\right)_{n}-\mathrm{R}_{\mathrm{F}} / \mathrm{CDPs}$ composites to afford higher adsorption ratios than the pristine CDPs. Interestingly, higher adsorption ratios from $25 \%$ to $95 \%$ were obtained with the increase of the oleophobicity of the VOCs as following:

benzene $<$ toluene $<o$-, $m$ - and $p$-xylenes

More interestingly, the highest adsorption ability toward these VOCs was observed by using the $\mathrm{R}_{\mathrm{F}}-\left(\mathrm{CH}_{2} \mathrm{CHSiO}_{2}\right)_{n}-\mathrm{R}_{\mathrm{F}} / \beta$-CDP composites. This finding is due to the size-fitness of the interior cavity of $\beta$-CDP toward these aromatic VOCs.

\section{Conclusion}

We have succeeded in preparing fluoroalkyl end-capped vinyltrimethoxysilane oligomer silica/ $\alpha$-, $\beta$-, $\gamma$-cyclodextrin polymers (CDPs) composites $\left[\mathrm{R}_{\mathrm{F}}-\left(\mathrm{CH}_{2} \mathrm{CHSiO}_{2}\right)_{n}-\mathrm{R}_{\mathrm{F}} / \mathrm{CDPs}\right]$ by the sol-gel reactions of the corresponding oligomer in the presence of CDPs under alkaline conditions. These obtained fluorinated composites were found to exhibit a superoleophilic/superhydrophobic characteristic on the modified surface, although the corresponding fluoroalkyl 
end-capped oligomeric silica nanoparticles can give an oleophobic/superhydrophobic property on the modified surface. The $\mathrm{R}_{\mathrm{F}}-\left(\mathrm{CH}_{2} \mathrm{CHSiO}_{2}\right)_{n}-\mathrm{R}_{\mathrm{F}} / \mathrm{CDP}$ composites possessing a superoleophilic/superhydrophibic characteristic have been applied to the packing material for the column chromatography to separate the mixture of oil/water and the W/O emulsions to isolate the transparent colorless oils. In addition, the $\mathrm{R}_{\mathrm{F}}-\left(\mathrm{CH}_{2} \mathrm{CHSiO}_{2}\right)_{n}-\mathrm{R}_{\mathrm{F}} / \mathrm{CDPs}$ composites have been also applied to the packing material for the solid-phase extraction cartridge to absorb the aromatic compounds such as BPA and BPAF in their aqueous solutions, and the highest adsorption behavior for these compounds was observed in the $\mathrm{R}_{\mathrm{F}}-\left(\mathrm{CH}_{2} \mathrm{CHSiO}_{2}\right)_{n}-\mathrm{R}_{\mathrm{F}} / \beta$-CDP composites. In addition to the adsorption of the aromatic compounds, the $\mathrm{R}_{\mathrm{F}}-\left(\mathrm{CH}_{2} \mathrm{CHSiO}_{2}\right)_{n}-\mathrm{R}_{\mathrm{F}} / \mathrm{CDPs}$ composites have been also applied to the adsorption of the VOCs by the head-space-GC/MS technique. In a wide variety of VOCs, more oleophilic aromatic VOCs can afford a higher adsorption ability toward the present $\mathrm{R}_{\mathrm{F}}-\left(\mathrm{CH}_{2} \mathrm{CHSiO}_{2}\right)_{n}-\mathrm{R}_{\mathrm{F}} / \mathrm{CDPs}$ composites, especially, the $\mathrm{R}_{\mathrm{F}}-\left(\mathrm{CH}_{2} \mathrm{CHSiO}_{2}\right)_{n}-\mathrm{R}_{\mathrm{F}} / \beta$-CDPs composites, compared to that of the pristine CDPs. In the cases of chlorinated aliphatic VOCs, tri- and tetra-chlorinated VOCs can provide a higher adsorption ability toward the fluorinated CDPs composites, especially fluorinated $\beta$-CDP composites. These findings would be due to the effective oleophilic-oleophilic interaction between the oleophilic VOCs and the fluorinated CDPs composites possessing a superoleophilic property. In this way, our present fluorinated CDPs composites would have high potential for the development of not only the practical oil/water separation materials but also the new sorbents to remove the organic pollutants in the industrial wastewater.

\section{Funding}

This work was partially supported by a Grant-in-Aid for Scientific Research 16K05891 from the Ministry of Education, Science, Sports, and Culture, Japan.

\section{Conflict of Interest}

The authors declare that they have no conflict of interest.

\section{References}

[1] Crini, G. and Badot, P.-M. (2010) Sorption Process and Pollution-Conventional and Non-Conventional Sorbents for Pollutant Removal from Wastewaters. Presses Universitaires de Franche-Comte, Besançon.

[2] Crini, G. (2005) Recent Developments in Polysaccharide-Based Materials Used as Adsorbents in Wastewater Treatment. Progress in Polymer Science, 30, 38-70. https://doi.org/10.1016/j.progpolymsci.2004.11.002

[3] Bender, M.L. and Komiyama, M. (1978) Cyclodextrin Chemistry. Spronger-Verlag, New York. https://doi.org/10.1007/978-3-642-66842-5

[4] Tabushi, I. (1982) Cyclodextrin Catalysis as a Model for Enzyme Action. Accounts of Chemical Research, 15, 66-72. https://doi.org/10.1021/ar00075a001

[5] Tang, S., Kong, L., Ou, J., Liu, Y. and Zou, H. (2006) Application of Cross-Linked 
$\beta$-Cyclodextrin Polymer for Adsorption of Aromatic Amino Acids. Journal of $\mathrm{Mo}$ lecular Recognition, 19, 39-48. https://doi.org/10.1002/jmr.756

[6] Asanuma, H., Kakazu, M., Shibata, M., Hishiya, T. and Komiyama, M. (1998) Synthesis of Molecularly Imprinted Polymer of $\beta$-Cyclodextrin for the Efficient Recognition of Cholesterol. Supramolecular Science, 5, 417-421.

https://doi.org/10.1016/S0968-5677(98)00042-X

[7] Crini, G., Cosentino, C., Bertini, S., Naggi, A., Torri, G., Vechhi, C., Janus, L. and Morcellet, M. (1998) Solid State NMR Spectroscopy Study of Molecular Motion in Cyclomaltoheptaose ( $\beta$-Cyclodextrin) Crosslinked with Epichlorohydrin. Carbohydrate Research, 308, 37-45. https://doi.org/10.1016/S0008-6215(98)00077-9

[8] Moine, L., Amiel, C., Brown, W. and Guerin, P. (2001) Associations between a Hydrophobically Modified, Degradable, Poly(malic acid) and a $\beta$-Cyclodextrin Polymer in Solution. Polymer International, 50, 663-676. https://doi.org/10.1002/pi.681

[9] Raoov, M., Mohamad, S. and Abas, M.R. (2014) Synthesis and Characterization of $\beta$-Cyclodextrin Functionalized Ionic Liquid Polymer as a Macroporous Material for the Removal of Phenols and As(V). International Journal of Molecular Sciences, 15, 100-119. https://doi.org/10.3390/ijms15010100

[10] Yamasaki, H., Nagasawa, Y., Uchida, N. and Fukunaga, K. (2013) Preparation of Spherical Photo-Crosslinkable Hydrogels Having $\beta$-Cyclodectrin Powdery Polymer and Their Application as Immobilizing Support for Microbes. Kobunshi Ronbun$s h u, 70,572-580$.

[11] Hishiya, T., Shibata, M., Kakazu, M., Asanuma, H. and Komiyama, M. (1999) Molecularly Imprinted Cyclodextrins as Selective Receptors for Steroids. Macromolecules, 32, 2265-2269. https://doi.org/10.1021/ma9816012

[12] Crini, G., Bertini, S., Torri, G., Naggi, A., Sforzini, D., Vecchi, C., Janus, L., Lekchiri, Y. and Morcellet, M. (1998) Sorption of Aromatic Compounds in Water Using Insoluble Cyclodextrin Polymers. Journal of Applied Polymer Science, 68, 1973-1978. https://doi.org/10.1002/(SICI)1097-4628(19980620)68:12<1973::AID-APP11>3.0.C $\mathrm{O} ; 2-\mathrm{T}$

[13] Kitaoka, M. and Hayashi, K. (2002) Adsorption of Bisphenol A by Cross-Linked $\beta$-Cyclodextrin Polymer. Journal of Inclusion Phenomena and Macrocyclic Chemistry, 44, 429-431. https://doi.org/10.1023/A:1023024004103

[14] Yu, J.C., Jiang, Z.T., Liu, H.Y., Yu, L. and Zhang, L. (2003) $\beta$-Cyclodextrin Epichlorohydrin Copolymer as a Solid-Phase Extraction Adsorbent for Aromatic Compounds in Water Samples. Analytica Chimica Acta, 477, 93-101. https://doi.org/10.1016/S0003-2670(02)01411-3

[15] Ameduri, B. and Sawada, H. (2016) Fluorinated Polymers: Volume 1, Synthesis, Properties, Processing and Simulation. RSC, Cambridge.

[16] Ameduri, B. and Sawada, H. (2016) Fluorinated Polymers: Volume 2, Applications. RSC, Cambridge.

[17] Sawada, H. (1996) Fluorinated Peroxides. Chemical Reviews, 96, 1779-1808. https://doi.org/10.1021/cr9411482

[18] Sawada, H. (2007) Synthesis of Self-Assembled Fluoroalkyl End-Capped Oligomeric Aggregates-Applications of These Aggregates to Fluorinated Oligomeric Nanocomposites. Progress in Polymer Science, 32, 509-533. https://doi.org/10.1016/j.progpolymsci.2007.02.002

[19] Sawada, H. (2012) Preparation and Applications of Novel Fluoroalkyl End-Capped Oligomeric Nanocomposites. Polymer Chemistry, 3, 46-65. 
https://doi.org/10.1039/C1PY00325A

[20] Sawada, H., Suzuki, T., Takashima, H. and Takishita, K. (2008) Preparation and Properties of Fluoroalkyl End-Capped Vinyltrimethoxysilane Oligomeric Nanoparticles-A New Approach to Facile Creation of a Completely Superhydrophobic Coating Surface with These Nanoparticles. Colloid and Polymer Science, 286, 1569-1574.

[21] Oikawa, Y., Saito, T., Yamada, S., Sugiya, M. and Sawada, H. (2015) Preparation and Surface Property of Fluoroalkyl End-Capped Vinyltrimethoxysilane Oligomer/Talc Composite-Encapsulated Organic Compounds: Application for the Separation of Oil and Water. ACS Applied Materials \& Interfaces, 7, 13782-13793. https://doi.org/10.1021/acsami.5b01588

[22] Suzuki, J., Takegahara, Y., Oikawa, Y., Chiba, M., Yamada, S., Sugiya, M. and Sawada, H. (2017) Preparation of Fluoroalkyl End-Capped Vinyltrimethoxysilane Oligomeric Silica/Poly(tetrafluoroethylene) Nanocomposites Possessing a Superoleophilic/Superhydrophobic Characteristic: Application to the Separation of Oil and Water. Journal of Sol-Gel Science and Technology, 81, 611-622. https://doi.org/10.1007/s10971-016-4209-7

[23] Sawada, H. and Nakayama, M. (1991) Synthesis of Fluorine-Containing Organosilicon Oligomers. Journal of the Chemical Society, Chemical Communications, 677-678. https://doi.org/10.1039/c39910000677

[24] Su, C., Wang, J., Chen, Z. and Chen, D. (2014) Durable Superhydrophobic and Superoleophilic Filter Paper for Oil-Water Separation Prepared by a Colloidal Deposition Method. Applied Surface Science, 313, 304-310. https://doi.org/10.1016/j.apsusc.2014.05.207

[25] Li, J., Wan, H., Ye, Y., Zhou, H. and Chen, J. (2012) One-Step Process to Fabrication of Transparent Superhydrophobic $\mathrm{SiO}_{2}$ Paper. Applied Surface Science, 261, 470-472. https://doi.org/10.1016/j.apsusc.2012.08.034

[26] Celia, E., Darmanin, T., de Givenchy, E.T., Amigoni, S. and Guiiard, F. (2013) Recent Advances in Designing Superhydrophobic Surfaces. Journal of Colloid and Interface Science, 402, 1-18. https://doi.org/10.1016/j.jcis.2013.03.041

[27] Liu, M. and Jiang, L. (2010) Switchable Adhesion on Liquid/Solid Interfaces. Advanced Functional Materials, 20, 3753-3764.

https://doi.org/10.1002/adfm.201001208

[28] Pan, Q.M., Wang, M. and Wang, H.B. (2008) Separating Small Amount of Water and Hydrophobic Solvents by Novel Superhydrophobic Copper Meshes. Applied Surface Science, 254, 6002-6006. https://doi.org/10.1016/j.apsusc.2008.03.034

[29] Wang, C.X., Yao, T.J., Wu, J., Ma, C., Fan, Z.X., Wang, Z.Y., Cheng, Y.R., Lin, Q. and Yang, B. (2009) Facile Approach in Fabricating Superhydrophobic and Superoleophilic Surface for Water and Oil Mixture Separation. ACS Applied Materials \& Interfaces, 1, 2613-2617. https://doi.org/10.1021/am900520z

[30] Wang, B., Li, J., Wang, G.Y., Liang, W.X., Zhang, Y.B., Shi, L., Guo, Z. and Liu, W.M. (2013) Methodology for Robust Superhydrophobic Fabrics and Sponges from In Situ Growth of Transition Metal/Metal Oxide Nanocrystals with Thiol Modification and Their Applications in Oil/Water Separation. ACS Applied Materials \& Interfaces, 5, 1827-1839. https://doi.org/10.1021/am303176a

[31] Liang, W.X. and Guo, Z.G. (2013) Stable Superhydrophobic and Superoleophilic Soft Porous Materials for Oil/Water Separation. RSC Advances, 3, 16469-16474.

[32] Zhang, J. and Seeger, S. (2019) Polyester Materials with Superwetting Silicone Nanofilaments for Oil/Water Separation and Selective Oil Absorption. Advanced 
Functional Materials, 21, 4699-4704.

[33] Zhou, X.Y., Zhang, Z.Z., Xu, X.H., Guo, F., Zhu, X.T., Men, X.H. and Ge, B. (2013) Robust and Durable Superhydrophobic Cotton Fabrics for Oil/Water Separation. ACS Applied Materials \& Interfaces, 5, 7208-7214. https://doi.org/10.1021/am4015346

[34] Wang, S.H., Li, M. and Lu, Q.H. (2010) Filter Paper with Selective Absorption and Separation of Liquids that Differ in Surface Tension. ACS Applied Materials \& Interfaces, 2, 677-683. https://doi.org/10.1021/am900704u

[35] Liu, X., Ge, L., Li, W., Wang, X. and Li, F. (2015) Layered Double Hydroxide Functionalized Textile for Effective Oil/Water Separation and Selective Oil Adsorption. ACS Applied Materials \& Interfaces, 7, 791-800.

[36] Zhang, M., Wang, C., Wang, S., Shi, Y. and Li, J. (2013) Fabrication of Superhydrophobic Cotton Textiles for Water-Oil Separation Based on Drop-Coating Route. Carbohydrate Polymers, 97, 59-64. https://doi.org/10.1016/j.carbpol.2012.08.118

[37] Arbatan, T., Zhang, L., Fang, X.-Y. and Shen, W. (2012) Cellulose Nanofibers as Binder for Fabrication of Superhydrophobic Paper. Chemical Engineering Journal, 210, 74-79. https://doi.org/10.1016/j.cej.2012.08.074

[38] Sawada, H., Suto, Y., Saito, T., Oikawa, Y., Yamashita, K., Yamada, S., Sugiya, M. and Suzuki, J. (2017) Preparation of RF-(VM-SiO2)n-RF/AM-Cellu Nanocomposites, and Use Thereof for the Modification of Glass and Filter Paper Surfaces: Creation of a Glass Thermoresponsive Switching Behavior and an Efficient Separation Paper Membrane. Polymers, 9, 92. https://doi.org/10.3390/polym9030092

[39] Katayama, S., Fujii, S., Saito, T., Yamazaki, S. and Sawada, H. (2017) Preparation of Fluoroalkyl End-Capped Vinyltrimethoxysilane Oligomeric Silica Nanocomposites Containing Gluconamide Units Possessing Highly Oleophobic/Superhydrophobic, Highly Oleophobic/Superhydrophilic, and Superoleophilic/Superhydrophobic Characteristics on the Modified Surfaces. Polymers, 9, 292.

[40] Crini, G. (2003) Studies on Adsorption of Dyes on Beta-Cyclodextrin Polymer. Bioresource Technology, 90, 193-198. https://doi.org/10.1016/S0960-8524(03)00111-1

[41] Weickenmeier, M., Wenz, G. and Huff, J. (1997) Association Thickener by Host Guest Interaction of a $\beta$-Cyclodextrin Polymer and a Polymer with Hydrophobic Side-Groups. Macromolecular Rapid Communications, 18, 1117-1123. https://doi.org/10.1002/marc.1997.030181216

[42] Sreenivasan, K. (1998) Solvent Effect on the Interaction of Steroids with a Novel Methyl $\beta$-Cyclodextrin Polymer. Journal of Applied Polymer Science, 68, 1857-1861.

https://doi.org/10.1002/(SICI)1097-4628(19980613)68:11<1857::AID-APP17>3.0.C $\underline{\mathrm{O} ; 2-\mathrm{R}}$

[43] Binello, A., Robaldo, B., Barge, A., Cavalli, R. and Cravotto, G. (2008) Synthesis of Cyclodextrin-Based Polymers and Their Use as Debittering Agents. Journal of Applied Polymer Science, 107, 2549-2557. https://doi.org/10.1002/app.27249

[44] Kiji, J., Kunishi, H., Okano, T., Terashima, T. and Motomura, K. (1992) Adsorption of Organic Species by a Cyclodextrin Epichlorohydrin Network Polymer. Angewandte Makromolekulare Chemie, 199, 207-210. https://doi.org/10.1002/apmc.1992.051990116

[45] Yamasaki, H., Makihara, Y. and Fukunaga, K. (2006) Efficient Phenol Removal of Wastewater from Phenolic Resin Plants Using Crosslinked Cyclodextrin Particles. Journal of Chemical Technology \& Biotechnology, 81, 1271-1276. 
https://doi.org/10.1002/jctb.1545

[46] Lee, K.-P., Choi, S.-H., Ryu, E.-N., Ryoo, J.J., Park, J.H., Kim, Y. and Hyun, M.H. (2002) Preparation and Characterization of Cyclodextrin Polymer and Its High-Performance Liquid-Chromatography Stationary Phase. Analytical Sciences, 18, 31-34.

[47] Kota, A.K., Kwon, G., Choi, W., Mabry, J.M. and Tuteja, A. (2012) Hygro-Responsive Membranes for Effective Oil-Water Separation. Nature Communications, 3, 1025-1032. https://doi.org/10.1038/ncomms2027

[48] Parak, S., Lee, E.S. and Sulaiman, W.R.W. (2015) Adsorption Behaviors of Surfactants for Chemical Flooding in Enhanced Oil Recovery. Journal of Industrial and Engineering Chemistry, 21, 1239-1245. https://doi.org/10.1016/j.jiec.2014.05.040 